\title{
Investigation of Concentration-Dependence of Thermodynamic Properties of Lanthanum, Yttrium, Scandium and Terbium in Eutectic LiCl-KCl Molten Salt
}

Yafei Wang, Wentao Zhou, and Jinsuo Zhang

Nuclear Engineering Program, Department of Mechanical and Aerospace Engineering, The Ohio State University, Columbus, Ohio 43210, USA

\begin{abstract}
Thermodynamic properties of rare earth metals in LiCl-KCl molten salt electrolyte are crucial to the development of electrochemical separation for the treatment of used nuclear fuels. In the present study, activity coefficient, apparent potential, and diffusion coefficient of lanthanum, yttrium, scandium, and terbium in the molten salt (58 at $\% \mathrm{LiCl}$ and $42 \mathrm{at} \% \mathrm{KCl}$ ) were calculated by the method of molecular dynamics simulation up to a concentration around 3 at $\%$ at temperatures of $723 \mathrm{~K}$ and $773 \mathrm{~K}$. It was found that the activity coefficient and the apparent potential increase with the species concentration while diffusion coefficient shows a trend of increase followed by decrease. The calculated results were validated by available measurement data of dilution cases. This research extends the range of data to a wide component and would provide further insight to the pyroprocessing design and safeguards.
\end{abstract}

Key words: Electrochemical separation; activity coefficient; apparent potential; diffusion coefficient; molten salt; molecular dynamics simulation.

\section{Introduction}

Reprocessing of spent nuclear fuel (SNF) is an important step in nuclear fuel cycle with the purpose of minimizing the environmental impact and recycling useful elements [1]. Advanced method exploration to process SNF has been adopted as one of the main features for GEN IV nuclear reactors [2]. Although only solvent extraction processes are commercialized currently $[3,4]$, pyroprocessing is being considered as a prominent way to recover long-lived elements by several countries, i.e. U.S.A, Japan, and Korea $[1,5,6]$. The core technology of pyroprocessing is the electrorefiner where actinides are separated with lanthanide fission products [7]. SNF is loaded into basket immersed in melts as the anode. When it is charged, the alkali metals, alkaline earth metals, rare earth elements, and actinides will anodically dissolve into the molten salt. $U$ selectively deposit on solid cathode while $\mathrm{Pu}$ together with minor actinides and residual $\mathrm{U}$ deposit on the liquid cadmium cathode or a new solid cathode after being accumulated [8]. The system is more compact compared with traditional PUREX process and expected to have the potential of economic advantage $[9,10]$. Also, due to the high resistance of inorganic melts to radiolytic degradation, pyroprocessing has the capability to handle "hot" SNF, which can 
reprocess SNF timely and save long time of storage [4,11]. It was designed firstly for metallic fuel treatment but can also processing oxide fuel with an additional step of fuel reduction [5].

Thermodynamic and electrochemical properties of elements in molten salt determine how they can transport and separate in the electrorefining cell [7,11,12]. For instance, diffusion coefficient affects species' transport in bulk electrolyte and electrolyte-electrode surface $[13,14]$ and activity coefficient provides information about the distribution coefficient and separation factor $[15,16]$. These properties are critical to pyroprocessing system design and safeguards as well as the prediction of system performance. Correspondingly, massive effort has been thrust to explore these data experimentally using electrochemical techniques, such as cyclic voltammetry (CV), chronopotentiometry (CP) and electromotive force (EMF) methods [17- 28]. Nevertheless, most of these researches only studied thermodynamic properties in infinite dilutions or were based on the assumption of the infinite dilution even though some studies have been done at different temperatures. It should be noticed that the concentration of an element in the salt could be pretty high in a practical separation process [29] for which the infinite dilution assumption cannot be applied. Therefore, significant deviation may be generated when these data are involved in model development. Considering the gap between previous researches and practical application, further fundamental understandings are still needed, such as thermodynamic and transport data of actinides and rare earth metals in the high-concentrated molten salt to improve the design of an electrochemical separation facility and provide information for safeguarding the facility [30].

Due to the harsh environment of experiments, such as high temperature, corrosion of molten salt, and radioactivity of elements, simulation method with Born-Mayer-Huggins [31] potential was applied in the study which has been successfully used to predict the structure, dynamic properties, and phase diagram of molten salt [32-35]. The activity coefficients, apparent potentials and diffusion coefficients of lanthanum, yttrium, scandium and terbium in $\mathrm{LiCl}-\mathrm{KCl}$ molten salt were calculated up to a high concentration of around 3 at $\%$ based on our previous simulation model [6] and their concentration dependence was investigated. Apparent potential was derived from the activity coefficient which was calculated by excess Gibbs free energy obtained by molecular dynamic (MD) simulations. After that, diffusivity could be obtained based on the relationship between activity coefficient and self-diffusivity which was also obtained by MD simulation. Based on the present simulations, the relationships between activity coefficient and material concentration were reported. The results indicate that the activity coefficient and apparent potential increase with mole fraction of the targeted ions while diffusion coefficient gives a trend of increase followed by decrease. Moreover, the comparison of diffusion coefficients at the temperatures of $723 \mathrm{~K}$ and $773 \mathrm{~K}$ of the same element as well as the comparison of activity coefficients of different elements at the same temperature were also discussed. This study offers us a compressive understanding of the thermodynamic properties of elements in $\mathrm{LiCl}-\mathrm{KCl}$ molten salt corresponding to the practical range of component in pyroprocessing. It will benefit 
the optimization of the pyroprocessing system and help it to apply to industry scale from laboratory one.

\section{Methodology and simulation details}

The details of the simulation methodology were described by Zhou and Zhang [6].

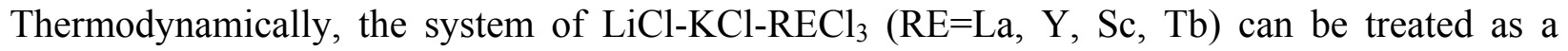
homogeneous binary solution because the composition of $\mathrm{LiCl}-\mathrm{KCl}$ does not change for all the calculations. Therefore, the total Gibbs free energy can be expressed by

$$
G_{\text {real }}=n_{1}\left(\mu_{1}^{0}+R T \ln x_{1}+R T \ln \gamma_{1}\right)+n_{2}\left(\mu_{2}{ }^{0}+R T \ln x_{2}+R T \ln \gamma_{2}\right)
$$

where $\mu_{1}{ }^{0}$ and $\mu_{2}{ }^{0}$ are the chemical potentials of the pure component 1 and $2, R$ is the gas constant, $T$ is the temperature in kelvin, $n_{1}$ and $n_{2}$ are the mole numbers of these two components, $x_{1}$ and $x_{2}$ are the mole fractions of component 1 and 2 respectively, $\gamma_{1}$ and $\gamma_{2}$ are the activity coefficients of component 1 and 2 respectively.

For the ideal solution, the activity coefficient of every component is unit, so the total Gibbs free energy is simplified into

$$
G_{\text {ideal }}=n_{1}\left(\mu_{1}^{0}+R T \ln x_{1}\right)+n_{2}\left(\mu_{2}^{0}+R T \ln x_{2}\right)
$$

Thus, the excess Gibbs free energy is

$$
G_{\text {excess }}=G_{\text {real }}-G_{\text {ideal }}=n_{1} R T \ln \gamma_{1}+n_{2} R T \ln \gamma_{2}
$$

With respect to the mole number $n_{1}$, the partial derivative should be

$$
\begin{aligned}
\left(\frac{\partial G_{\text {excess }}}{\partial n_{1}}\right)_{n_{2}, p, T} & =R T \ln \gamma_{1}+n_{1} R T \frac{\partial \ln \gamma_{1}}{\partial n_{1}}+n_{2} R T \frac{\partial \ln \gamma_{2}}{\partial n_{1}} \\
& =R T \ln \gamma_{1}
\end{aligned}
$$

Hence, the activity coefficient $\gamma_{1}$ can be calculated by excess Gibbs free energy.

During the calculation process of $G_{\text {ideal }}$ and $G_{\text {real }}$, free energy of $\mathrm{RECl}_{3}$ in eutectic molten salt and pure $\mathrm{RECl}_{3}$ crystal can be calculated through thermodynamic integration [36] in our simulation. It should be noticed that no first-order phase transitions should be encountered along the integration path. In our study, we used the method of coupling parameters to decrease the interatomic potential of liquid to null potential which indicates final status of ideal gas through Gauss potential. The simulation was carried out in NVT ensemble, so the density keeps constant 
all the time. The final status is still kind of "liquid" but with an interatomic potential of zero. This method has been applied successfully to predict the phase diagram of $\mathrm{KCl}$ [37]. Also, we have checked the consistence of forward and backward integrations to make sure its reversibility. Figure 1 and Figure 2 show an example of the results for LiCl-KCl molten salt at $773 \mathrm{~K}$, which indicates results from backward and forward integration almost coincide. Therefore, we believe that the integration path we used for liquid is fine with avoiding first order transition. Crystal $\mathrm{RECl}_{3}$ was transferred to Einstein crystal to obtain its Gibbs energy. Because of similarity of start and final statuses, there should not be first order transition as well.

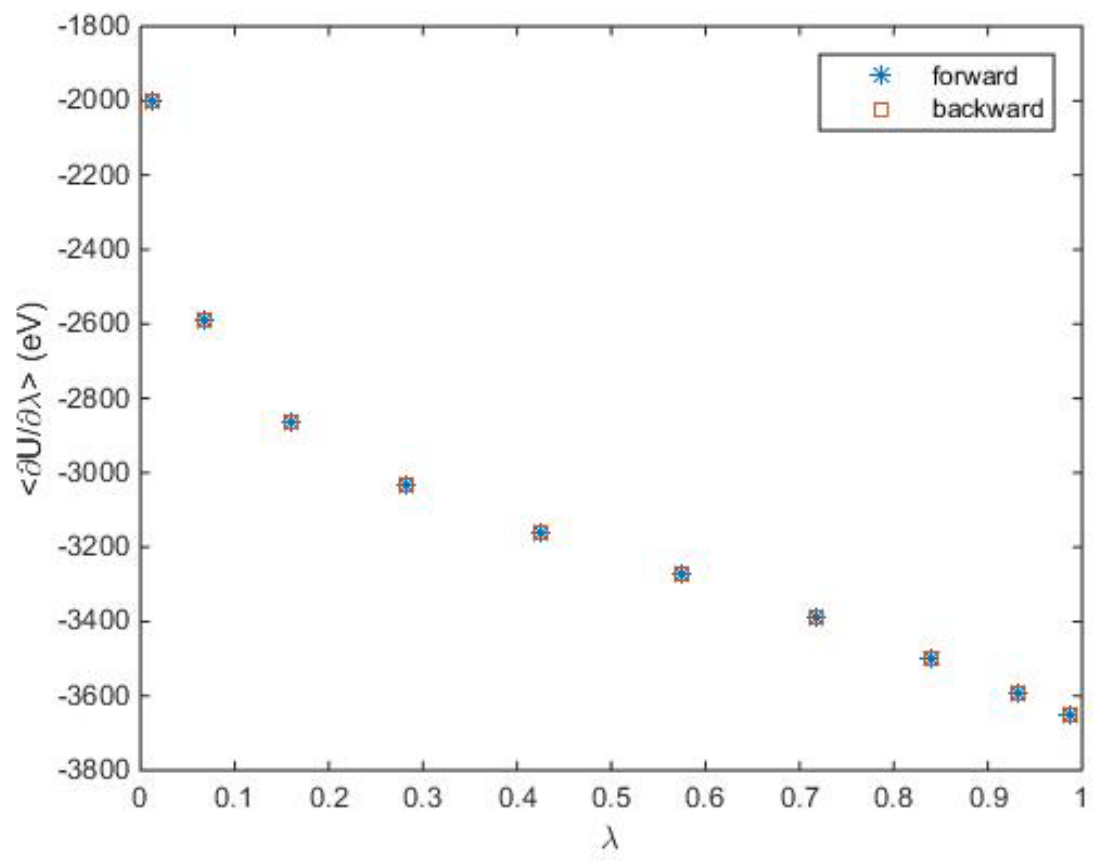

Figure 1. Transformation from potential of $\mathrm{LiCl}-\mathrm{KCl}$ to Gauss potential at $773 \mathrm{~K}$ 


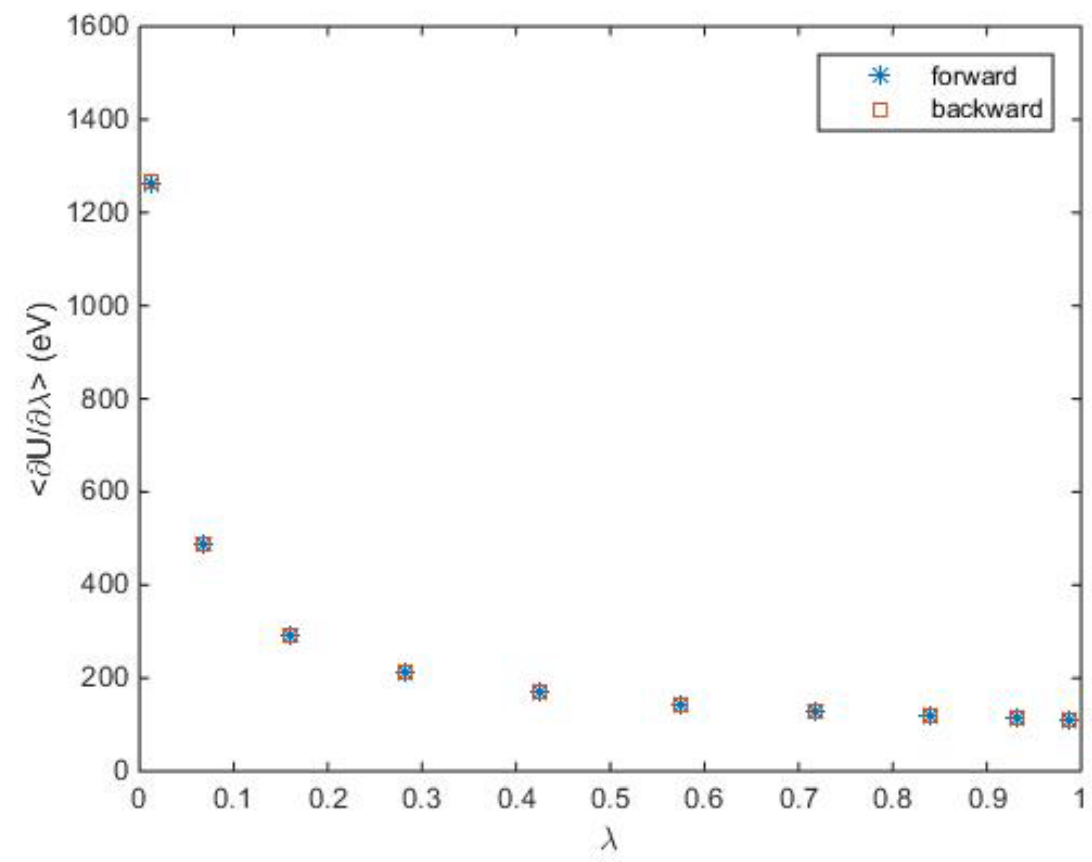

Figure 2. Transformation of Gauss potential to null potential at $773 \mathrm{~K}$

For the calculation of self-diffusion coefficient, it is related to the mean squared displacement (MSD) by $[38,39]$

$$
D_{s}=\frac{1}{6} \lim _{t \rightarrow \infty} \frac{d}{d t}(M S D)
$$

where $D_{S}$ is the self-diffusion coefficient, $t$ is time. $M S D$ is determined by [39]

$$
M S D=\left\langle\left(p(t)-p_{0}\right)^{2}\right\rangle=\frac{1}{N} \frac{1}{n_{t}} \sum_{j=1}^{n_{t}} \sum_{i=1}^{N}\left(p_{i}\left(t_{0 j}+t\right)-p_{i}\left(t_{0 j}\right)\right)^{2}
$$

where $p(t)$ is the positon at the time of $t$ and $p_{0}$ is the initial position, $N$ is the atom number, $n_{t}$ is the time origins number, $t_{0 j}$ is the initial timestep at time $j$. However, what we need is the chemical diffusion coefficient, also called diffusivity, it can be expressed by [40]

$$
D_{c}=D_{s}\left(1+\frac{d \ln \gamma}{d \ln x}\right)
$$

where $D_{c}$ is the chemical diffusion coefficient, $\gamma$ is activity coefficient and $x$ is mole fraction. 
As for the simulation details, molecular dynamics simulation and thermodynamic integration [36] were used in this research. For the free energy calculation, solution was transferred to ideal gas through Gauss potential while crystal was transferred to Einstein crystal [6]. All of our simulations were run with molecular dynamics software LAMMPS [41,42]. The potential we used is the Born-Mayer-Huggins potential which has been widely employed in recent studies $[43,44,45,37]$ for thermodynamic modelling and has successfully predicted structure, phase diagram, diffusion coefficient, and other properties of halides and also $\mathrm{RECl}_{3}$ system. Parameters used are listed in Table 1.

Table 1. The Born-Mayer-Huggins potential parameters used in the simulation [1]

\begin{tabular}{|c|c|c|c|c|c|}
\hline Pair & $A / e V$ & $\rho / \AA$ & $\sigma / \AA$ & $C / e V \cdot \AA^{6}$ & $D / e V \cdot \AA^{8}$ \\
\hline$C l^{-}-C l^{-}$ & 0.17408 & 0.34586 & 3.340 & 132.6892 & -1245.0685 \\
\hline$C l^{-}-L i^{+}$ & 0.17289 & 0.33921 & 2.570 & 1.2477 & -1.5030 \\
\hline$C l^{-}-K^{+}$ & 0.13738 & 0.34140 & 3.190 & 29.9336 & -45.4741 \\
\hline$C l^{-}-L a^{3+}$ & 0.77553 & 0.29399 & 2.842 & 58.0907 & -100.3933 \\
\hline$L i^{+}-L i^{+}$ & 0.26089 & 0.33705 & 1.800 & 0.0478 & -0.0167 \\
\hline$L i^{+}-K^{+}$ & 0.21764 & 0.33705 & 2.420 & 0.8298 & -0.5344 \\
\hline$L i^{+}-L a^{3+}$ & 0.00215 & 0.17639 & 2.072 & 1.1413 & -0.5522 \\
\hline$K^{+}-K^{+}$ & 0.19011 & 0.33921 & 3.040 & 15.1519 & -14.9465 \\
\hline$K^{+}-L a^{3+}$ & 0.00006 & 0.17639 & 2.692 & 20.7936 & -15.8287 \\
\hline$L a^{3+}-L a^{3+}$ & 0.00069 & 0.17639 & 2.344 & 28.5016 & -16.7322 \\
\hline$C l^{-}-Y^{3+}$ & 0.73713 & 0.29399 & 2.710 & 24.8030 & -75.2950 \\
\hline$L i^{+}-Y^{3+}$ & 0.00455 & 0.17639 & 1.940 & 0.5378 & -0.3514 \\
\hline$K^{+}-Y^{3+}$ & 0.00014 & 0.17639 & 2.560 & 9.7694 & -10.0059 \\
\hline$Y^{3+}-Y^{3+}$ & 0.00309 & 0.17639 & 2.080 & 6.2919 & -6.6929 \\
\hline$C l^{-}-S c^{3+}$ & 0.80056 & 0.29399 & 2.555 & 17.9435 & -50.1967 \\
\hline$L i^{+}-S c^{3+}$ & 0.01096 & 0.17639 & 1.785 & 0.3944 & -0.2175 \\
\hline$K^{+}-S c^{3+}$ & 0.00033 & 0.17639 & 2.405 & 7.2240 & -6.1240 \\
\hline$S c^{3+}-S c^{3+}$ & 0.01790 & 0.17639 & 1.770 & 3.4417 & -2.5098 \\
\hline$C l^{-}-T b^{3+}$ & 0.70863 & 0.29399 & 2.733 & 32.2062 & -133.8578 \\
\hline$L i^{+}-T b^{3+}$ & 0.00400 & 0.17639 & 1.963 & 0.6752 & -0.4016 \\
\hline$K^{+}-T b^{3+}$ & 0.00012 & 0.17639 & 2.583 & 12.3627 & -11.1939 \\
\hline$T b^{3+}-T b^{3+}$ & 0.00238 & 0.17639 & 2.126 & 10.0801 & -8.3661 \\
\hline
\end{tabular}

For the calculation of the Gibbs free energy of molten $\mathrm{LiCl}-\mathrm{KCl}$ at the temperatures of $773 \mathrm{~K}$ and $723 \mathrm{~K}, 400 \mathrm{Cl}^{-}, 232 \mathrm{Li}^{+}$and $168 \mathrm{~K}^{+}$was performed firstly. Then, in order to realize calculating Gibbs free energy of $\mathrm{RECl}_{3}$ in the molten $\mathrm{LiCl}-\mathrm{KCl}$ with different concentrations, 1-6 $\mathrm{RECl}_{3}$ were added to $116 \mathrm{Li}^{+}, 84 \mathrm{~K}^{+}$and $200 \mathrm{Cl}^{-}$system separately. With regard to the 
calculation of Gibbs free energy of eutectic $\mathrm{LiCl}-\mathrm{KCl}$ and $\mathrm{LiCl}-\mathrm{KCl}-\mathrm{RECl}_{3}$, initial configurations with the temperatures of $773 \mathrm{~K}, 723 \mathrm{~K}$ and pressure of 1 bar were set respectively. The simulations were firstly equilibrated in an NVE ensemble for 10,000 steps, an NVT ensemble for 100,000 steps and then an NPT ensemble for 200,000 steps. During the equilibrium process, the temperature was adjusted from $800 \mathrm{~K}$ to $773 \mathrm{~K}$ and $723 \mathrm{~K}$ respectively for the sake of making simulation results more smooth and correct. Average volume of the system was obtained by averaging the volume dumped by the 200,000 steps in the NPT ensemble and then used to calculate the free energy in the NVT ensemble at the temperatures of $773 \mathrm{~K}$ and $723 \mathrm{~K}$ respectively. 10-point Gauss-Legendre quadrature was chosen as $\lambda$ (coupling parameter of potential transformation) in the process of calculating the free energy by thermodynamic integration method and 2000,000 steps were set in NVT ensemble for every $\lambda$. The Gauss potential parameters $\alpha$ and $\delta$ used in the simulations were chosen as $21.453 \mathrm{eV}$ and $0.72 \AA$ separately [46].The time step of all of all simulations was $1 \mathrm{fs}$.

In order to calculate the Gibbs free energy of $\mathrm{RECl}_{3}$, the lattice should be defined firstly. The initial configuration is made under the case of no atoms losing during the simulation process. The unit cells and initial configuration of $\mathrm{RECl}_{3}$ is given in Table 2 [47]. During the process of system equilibrium, the temperature of $800 \mathrm{~K}$ and pressure of 1 bar were set as the initial state, then the system ran 10,000 steps in the NVE ensemble, 100,000 steps in the NVT ensemble to adjust the temperature from $800 \mathrm{~K}$ to $773 \mathrm{~K}$ and $723 \mathrm{~K}$ respectively and 500,000 steps in NPT ensemble to obtain the average volume which was used to calculate free energy after that. Thermodynamic integration of adiabatic switching [48] are used in the calculation of free energy, we ran 50,000 steps to equilibrate the system at $\lambda=0$ and 100,000 steps to vary $\lambda$ from 0 to 1 .

Table 2. Unit cells and initial configuration of $\mathrm{RECl}_{3}$

\begin{tabular}{|c|c|c|c|c|c|c|c|}
\hline Component & $\mathrm{a} / \AA$ & $\mathrm{b} / \AA$ & $\mathrm{c} / \AA$ & $\alpha$ & $\beta$ & $\gamma$ & $\begin{array}{c}\text { Initial } \\
\text { configuration }\end{array}$ \\
\hline $\mathrm{LaCl}_{3}$ & 7.603 & 7.603 & 4.375 & $90.000^{\circ}$ & $90.000^{\circ}$ & $120.000^{\circ}$ & $5 \times \mathrm{a}, 4 \times \mathrm{b}, 5 \times \mathrm{c}$ \\
\hline $\mathrm{YCl}_{3}$ & 7.066 & 6.993 & 6.993 & $119.853^{\circ}$ & $99.765^{\circ}$ & $99.765^{\circ}$ & $5 \times \mathrm{a}, 5 \times \mathrm{b}, 4 \times \mathrm{c}$ \\
\hline $\mathrm{ScCl}_{3}$ & 7.453 & 7.453 & 7.453 & $51.648^{\circ}$ & $51.648^{\circ}$ & $51.648^{\circ}$ & $10 \times \mathrm{a}, 5 \times \mathrm{b}, 2 \times \mathrm{c}$ \\
\hline $\mathrm{TbCl}_{3}$ & 6.531 & 6.531 & 11.735 & $90.000^{\circ}$ & $90.000^{\circ}$ & $90.000^{\circ}$ & $5 \times \mathrm{a}, 5 \times \mathrm{b}, 2 \times \mathrm{c}$ \\
\hline
\end{tabular}

For the calculation of the diffusion coefficient, we used LAMMPS to track the trajectory of $\mathrm{RE}^{3+}$ at different time and then used it to get the result of MSD. $1160 \mathrm{Li}^{+}, 840 \mathrm{~K}^{+}$and $2000 \mathrm{Cl}^{-}$were used in the initial configuration and then $10,15,20,2530,35,40,45,50,55$ and $60 \mathrm{RECl}_{3}$ were added to the systems respectively to perform the calculations of diffusion coefficients at different concentrations. The simulations were initially ran in NVE ensemble for 50,000 steps and then 500,000 steps in NPT ensemble and 500,000 steps in NVT ensemble eventually. The positions were dumped every 1000 steps in NVT ensemble for 200,000 steps totally and the time step was $1 \mathrm{fs}$. 


\section{Results}

The Gibbs free energy for the real solution can be obtained directly from the simulation while that for the ideal solution can be got from equation (2), where Gibbs free energy of supercooled $\operatorname{RECl}_{3}\left(\mu_{1}{ }^{0}\right.$ in equation (2)) and pure LiCl-KCl molten salt $\left(\mu_{2}{ }^{0}\right.$ in equation (2)) should be calculated firstly through the simulation. Since at temperatures of $723 \mathrm{~K} / 773 \mathrm{~K}$ and one atmosphere pressure, the physical status of $\mathrm{LaCl}_{3}, \mathrm{YCl}_{3}, \mathrm{ScCl}_{3}$ and $\mathrm{TbCl}_{3}$ are all crystal, we need to transfer the Gibbs free energy of crystal $\mathrm{RECl}_{3}$ to the supercooled $\mathrm{RECl}_{3}$, which can be realized by

$$
G_{s c, R E C l_{3}}=G_{\text {crystal }, R E C l_{3}}+\Delta G_{f u s i o n, R E C l_{3}}
$$

where $G_{\text {crystal }, R E}$ is the Gibbs free energy for crystal $\mathrm{RECl}_{3}, \Delta G_{\text {fusion }, R E}$ is the Gibbs free energy of fusion for $\mathrm{RECl}_{3}$ and it can be expressed by

$$
\Delta G_{f u s i o n, R E C l_{3}}=\Delta G_{s c, R E C l_{3}}-\Delta G_{c, R E C l_{3}}
$$

where $\Delta G_{s c, R E C l_{3}}$ and $\Delta G_{c, R E C l_{3}}$ are Gibbs free energy of formation for the supercooled and crystal status of species $\mathrm{RECl}_{3}$ respectively, which are shown in Table 3.

Table 3. Gibbs free energy of formation for supercooled and crystal $\mathrm{RECl}_{3}$

\begin{tabular}{|c|c|c|c|}
\hline Temperature & Component & $\Delta G_{s c, R E C l_{3}}(\mathrm{KJ} / \mathrm{mol})$ & $\Delta G_{c, R E C l_{3}}(\mathrm{KJ} / \mathrm{mol})$ \\
\hline \multirow{4}{*}{$723 \mathrm{~K}$} & $\mathrm{LaCl}_{3}$ & $-872.976[49]$ & $-910.7[50]$ \\
\cline { 2 - 4 } & $\mathrm{YCl}_{3}$ & $-820.979[49]$ & $-900.0[49]$ \\
\cline { 2 - 4 } & $\mathrm{ScCl}_{3}$ & $-729.047[51]$ & $-754.3[52]$ \\
\cline { 2 - 4 } & $\mathrm{TbCl}_{3}$ & $-813.517[53]$ & $-813.5[52]$ \\
\hline \multirow{3}{*}{$773 \mathrm{~K}$} & $\mathrm{LaCl}_{3}$ & $-854.870[49]$ & $-900.8[50]$ \\
\cline { 2 - 4 } & $\mathrm{YCl}_{3}$ & $-810.954[49]$ & $-892.1[49]$ \\
\cline { 2 - 4 } & $\mathrm{ScCl}_{3}$ & $-719.802[51]$ & $-743.1[52]$ \\
\cline { 2 - 4 } & $\mathrm{TbCl}_{3}$ & $-803.678[53]$ & $-803.7[52]$ \\
\hline
\end{tabular}

\section{Lanthanum}

Based on our modelling, the total Gibbs free energy for the ideal solution and real solution, excess Gibbs free energy and molar excess Gibbs free energy of the system of LiCl-KCl- $n \mathrm{LaCl}_{3}$ (the component of LiCl-KCl- $n \mathrm{LaCl}_{3}$ stands for $\mathrm{n} \mathrm{LaCl}_{3}$ were added to $116 \mathrm{Li}^{+}, 84 \mathrm{~K}^{+}$and 200 $\mathrm{Cl}^{-}$system) are obtained respectively, these values are presented in Table 4.

Table 4. The results of total Gibbs free energy for ideal solution and real solution, excess Gibbs free energy and molar excess Gibbs free energy of $\mathrm{LiCl}-\mathrm{KCl}-\mathrm{LaCl}_{3}$ mixture 


\begin{tabular}{|c|c|c|c|c|c|c|}
\hline Temperature & Component & $G_{\text {real }} / \mathrm{eV}$ & $G_{\text {ideal }} / \mathrm{eV}$ & $\begin{array}{l}G_{\text {excess }} \\
/ \mathrm{eV}\end{array}$ & $x_{L a}(\%)$ & $\begin{array}{l}\bar{G}_{\text {excess }}(J \\
/ \text { mol })\end{array}$ \\
\hline \multirow{6}{*}{$723 \mathrm{~K}$} & $\mathrm{LiCl}-\mathrm{KCl}-1 \mathrm{LaCl}_{3}$ & -1802.9122 & -1802.5502 & -0.362 & 0.4975 & -173.7502 \\
\hline & LiCl-KCl-2 $\mathrm{LaCl}_{3}$ & -1846.9565 & -1846.3294 & -0.627 & 0.9901 & -299.5318 \\
\hline & $\mathrm{LiCl}-\mathrm{KCl}-3 \mathrm{LaCl}_{3}$ & -1890.8176 & -1890.0764 & -0.741 & 1.4778 & -352.3142 \\
\hline & LiCl-KCl-4 $\mathrm{LaCl}_{3}$ & -1934.9195 & -1933.8024 & -1.117 & 1.9608 & -528.3349 \\
\hline & LiCl-KCl-5 $\mathrm{LaCl}_{3}$ & -1978.6293 & -1977.5131 & -1.116 & 2.4390 & -525.3829 \\
\hline & LiCl-KCl-6 $\mathrm{LaCl}_{3}$ & -2022.6756 & -2021.2115 & -1.464 & 2.9126 & -685.7685 \\
\hline \multirow{6}{*}{$773 \mathrm{~K}$} & LiCl-KCl-1 $\mathrm{LaCl}_{3}$ & -1817.5271 & -1816.9724 & -0.555 & 0.4975 & -266.2688 \\
\hline & LiCl-KCl-2 $\mathrm{LaCl}_{3}$ & -1861.4071 & -1860.7750 & -0.632 & 0.9901 & -301.9138 \\
\hline & LiCl-KCl-3 $\mathrm{LaCl}_{3}$ & -1905.6210 & -1904.5431 & -1.078 & 1.4778 & -512.3313 \\
\hline & LiCl-KCl-4 $\mathrm{LaCl}_{3}$ & -1949.6779 & -1948.2889 & -1.389 & 1.9608 & -656.9860 \\
\hline & LiCl-KCl-5 $\mathrm{LaCl}_{3}$ & -1993.6683 & -1992.0181 & -1.650 & 2.4390 & -776.6617 \\
\hline & LiCl-KCl-6 $\mathrm{LaCl}_{3}$ & -2037.6830 & -2035.7343 & -1.949 & 2.9126 & -912.7331 \\
\hline
\end{tabular}

In Table 4, $x_{L a}$ is the mole fraction of $\mathrm{LaCl}_{3}$ in the solution and $\bar{G}_{\text {excess }}$ is the molar excess Gibbs free energy. Then the data of mole fraction $x_{L a}$ and molar excess Gibbs free energy $\bar{G}_{\text {excess }}$ were used to fit a curve by Margules model [54]which has been verified by many experimental data [55]. Since the value of $\bar{G}_{\text {excess }}$ is 0 when $x_{L a}=0$, so this data point was also used to fit the curve to make the result be more accurate, the fitting result is shown in Figure 3 . It can be seen the fitting result is quite well and then the activity coefficient can be calculated by

$$
\gamma=\exp \left(\frac{\bar{G}_{\text {excess }}+\left(1-x_{R E}\right) \frac{\partial \bar{G}_{\text {excess }}}{\partial x_{R E}}}{R T}\right)
$$

where $x_{R E}$ is the mole fraction of specie $R E$. The calculated results can be seen in Figure 4 . 


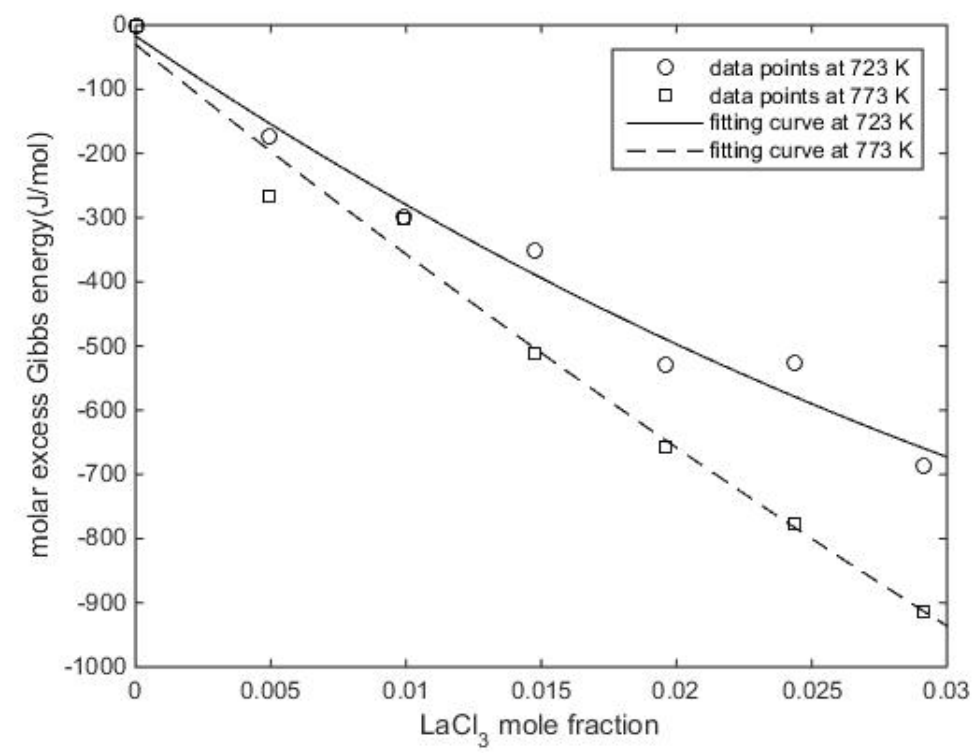

Figure 3. The fitting curve of molar excess Gibbs free energy to mole fraction of $\mathrm{LaCl}_{3}$ in the solution

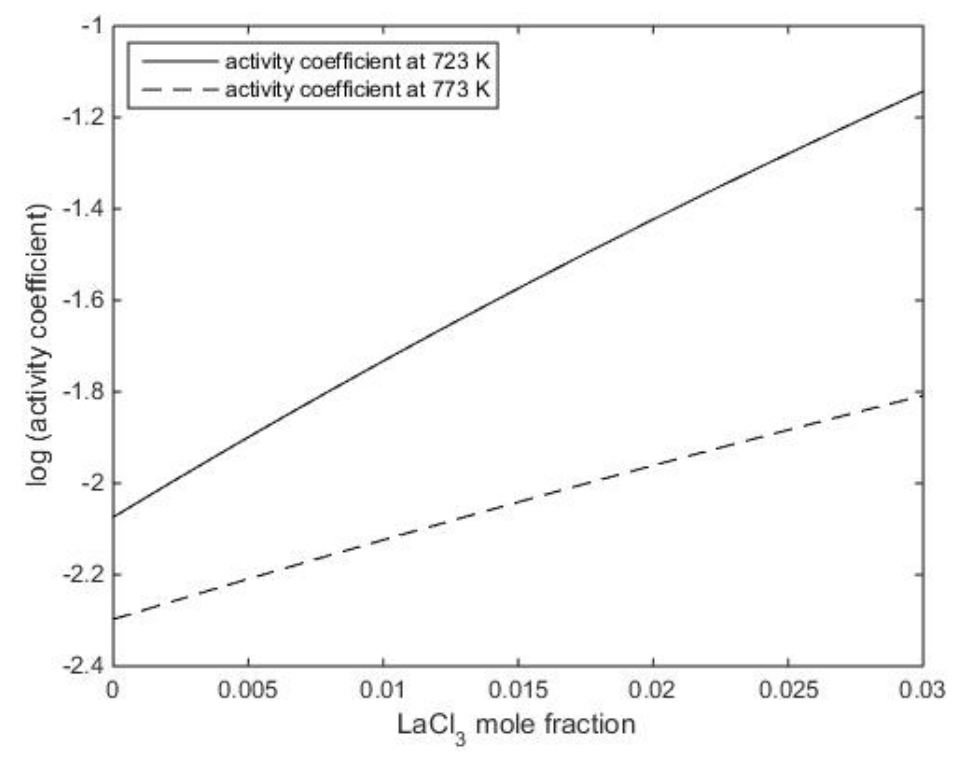

Figure 4. Activity coefficient of $\mathrm{LaCl}_{3}$ in eutectic molten salt at the temperatures of $723 \mathrm{~K}$ and $773 \mathrm{~K}$

Figure 4 presents our calculated results of activity coefficients of $\mathrm{La}^{3+}$ at different concentrations for the temperatures of $723 \mathrm{~K}$ and $773 \mathrm{~K}$. It should be noted that the values of Gibbs free energy of fusion are a little different in different literatures [49,50,52] and it has an influence on the calculated activity coefficients. So the imprecision on the values of Gibbs free energy of fusion will result in a small error in our results. Also, the comparisons of activity coefficients in other literatures [11,58] are based on the same order of magnitude. It should be thought the comparisons are acceptable if the calculated activity coefficients of $\mathrm{RECl}_{3}$ in molten salt and 
literature values are in the same order of magnitude. It can be seen the comparison in Table 5 with other literature at low concentration shows our work agrees quite well with that from others.

Table 5. Comparison between calculated activity coefficients of $\mathrm{LaCl}_{3}$ and literature values

\begin{tabular}{|c|c|c|c|}
\hline Temperature & Mole fraction & Calculated activity coefficient & Literature value \\
\hline \multirow{3}{*}{$723 \mathrm{~K}$} & Dilution & & $5.4 \times 10^{-3}[49]$ \\
\cline { 4 - 4 } & Dilution & \multirow{3}{*}{$8.4 \times 10^{-3} \sim 13.4 \times 10^{-3}$} & $4.7 \times 10^{-3}[56]$ \\
\cline { 4 - 4 } & Dilution & & $3.0 \times 10^{-3}[11]$ \\
\cline { 4 - 4 } & Dilution & & $1.4 \times 10^{-3}[57]$ \\
\hline \multirow{2}{*}{$773 \mathrm{~K}$} & $2.27 \times 10^{-3}$ & $5.5 \times 10^{-3}$ & $1.05 \times 10^{-3}[58]$ \\
\cline { 4 - 4 } & Dilution & $5.0 \times 10^{-3} \sim 6.4 \times 10^{-3}$ & $1.04 \times 10^{-3}[11]$ \\
\hline
\end{tabular}

a: the calculated results corresponding to the mole fraction of $0-5.80 \times 10^{-3}$.

Once the activity coefficients have been obtained, apparent standard potential can be calculated by

$$
E_{R E, c l^{-} / c l_{2}}^{a p, 0}=\frac{\Delta G_{s c, R E}}{3 F}+\frac{R T}{3 F} \ln \gamma
$$

where $E_{R E, c l^{-} / c l_{2}}^{a p, 0}$ is the apparent standard reduction potential of $R E^{3+} / R E$ in eutectic molten salt. $F$ is Faraday constant. Figure 5 presents the calculated results of apparent standard potential at the temperatures of $723 \mathrm{~K}$ and $773 \mathrm{~K}$. The comparison in Table 6 indicates that our calculated apparent standard potential agree well with other literature values.

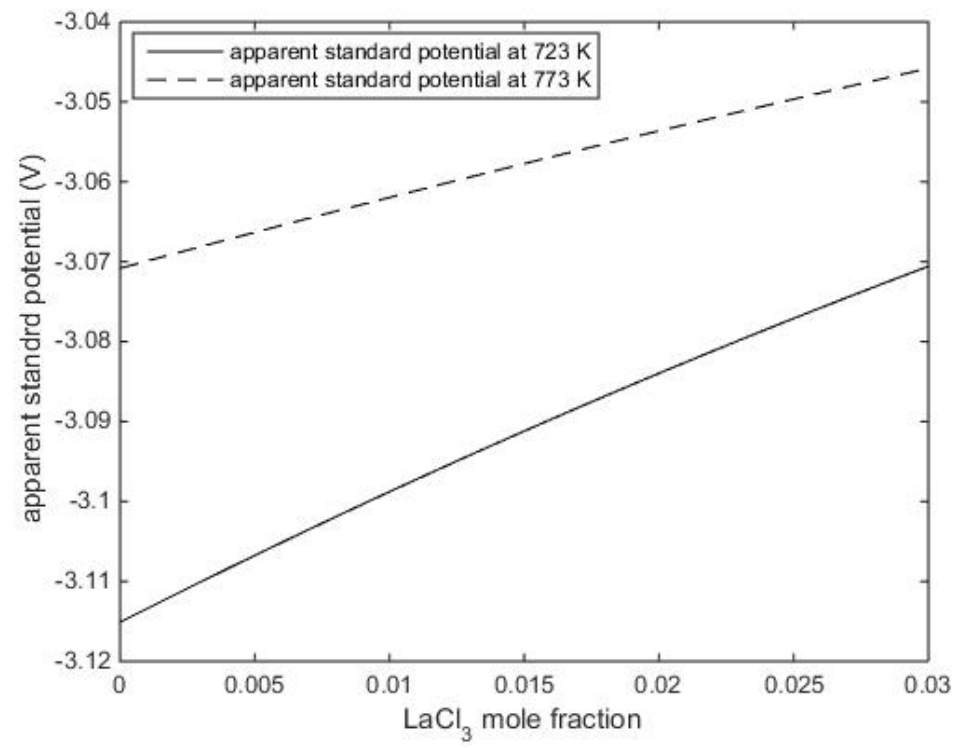

Figure 5. Apparent standard potential of $\mathrm{LaCl}_{3}$ at the temperatures of $723 \mathrm{~K}$ and $773 \mathrm{~K}$ 
Table 6. Comparison between the calculated apparent standard potential of $\mathrm{LaCl}_{3}$ and literature values

\begin{tabular}{|c|c|c|c|}
\hline Temperature & Mole fraction & Calculated results $(\mathrm{V})^{\mathrm{b}}$ & Literature value (V) \\
\hline \multirow{3}{*}{$723 \mathrm{~K}$} & Dilution & $-3.115 \sim-3.106$ & $-3.136[11]$ \\
\cline { 2 - 4 } & Dilution & $-3.115 \sim-3.106$ & $-3.124[49]$ \\
\cline { 2 - 4 } & $7.80 \times 10^{-3}$ & -3.102 & $-3.208[59]$ \\
\cline { 2 - 4 } & $4.66 \times 10^{-3}$ & -3.107 & $-3.267[60]$ \\
\cline { 2 - 4 } & $9.17 \times 10^{-3}$ & -3.100 & $-3.143[61]$ \\
\hline \multirow{3}{*}{$773 \mathrm{~K}$} & $4.66 \times 10^{-3}$ & -3.067 & $-3.216[60]$ \\
\cline { 2 - 4 } & Dilution & $-3.071 \sim-3.066$ & $-3.106[11]$ \\
\hline
\end{tabular}

$\mathrm{b}$ : the calculated results corresponding to the mole fraction of $0-5.80 \times 10^{-3}$.

The self-diffusion coefficients and chemical diffusion coefficients at the temperatures of $723 \mathrm{~K}$ and $773 \mathrm{~K}$ with different mole fractions were also calculated in the present study through the method of MD simulation. The relationship between diffusion coefficient and mole fraction is shown in Figure 6. The comparison between calculated chemical diffusion coefficients and literature values which can be seen in Table 7 indicates our calculated results agree well with previous studies.

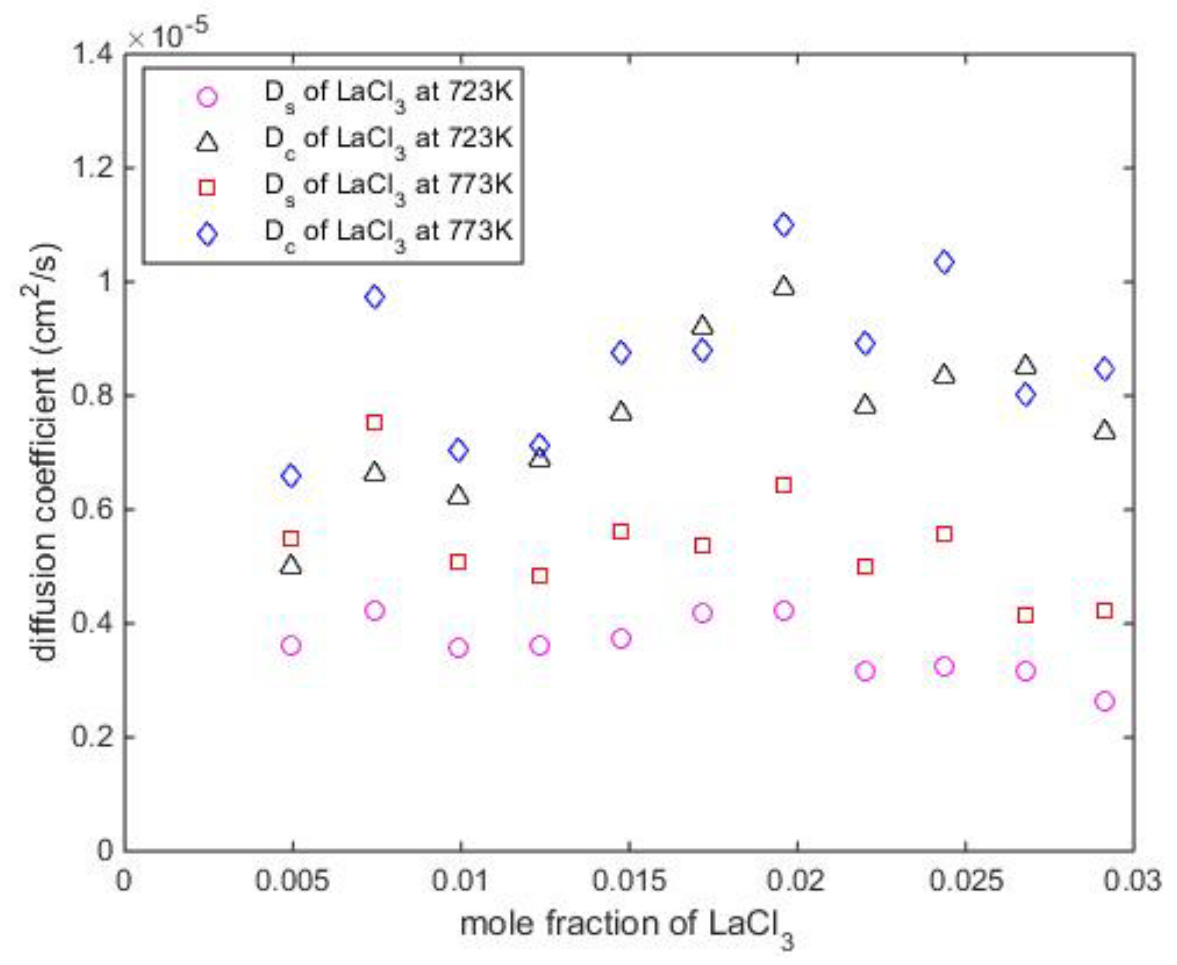

Figure 6. Self-diffusion coefficient and chemical diffusion coefficient of $\mathrm{LaCl}_{3}$ at the temperatures of $723 \mathrm{~K}$ and $773 \mathrm{~K}$ 
Table 7. Comparison between the calculated chemical diffusion coefficient of $\mathrm{LaCl}_{3}$ and literature values

\begin{tabular}{|c|c|c|}
\hline Temperature & The range of $\mathrm{D}_{\mathrm{c}}\left(\mathrm{cm}^{2} / \mathrm{s}\right)^{\mathrm{c}}$ & Literature value $\left(\mathrm{cm}^{2} / \mathrm{s}\right)$ \\
\hline \multirow{2}{*}{$723 \mathrm{~K}$} & \multirow{3}{*}{$5.1 \times 10^{-6} \sim 9.9 \times 10^{-6}$} & $11.5 \pm 1.2 \times 10^{-6}[62]$ \\
\cline { 3 - 3 } & & $14.7 \times 10^{-6}[59]$ \\
\hline \multirow{3}{*}{$773 \mathrm{~K}$} & \multirow{3}{*}{$6.6 \times 10^{-6} \sim 11.0 \times 10^{-6}$} & $10.0 \times 10^{-6}[60]$ \\
\cline { 3 - 3 } & & $8 \pm 5 \times 10^{-6}[63]$ \\
\hline
\end{tabular}

c: the range of $D_{c}$ corresponding to the mole fraction of $0.004975-0.029126$.

\section{Yttrium}

For yttrium, the total Gibbs free energy for the ideal solution and real solution, excess Gibbs free energy and molar excess Gibbs free energy are given in Table 8.

Table 8. The results of total Gibbs free energy for ideal solution and real solution, excess Gibbs free energy and molar excess Gibbs free energy of $\mathrm{LiCl}-\mathrm{KCl}-\mathrm{YCl}_{3}$ mixture

\begin{tabular}{|c|c|c|c|c|c|c|}
\hline Temperature & Component & $G_{\text {real }} / \mathrm{eV}$ & $G_{\text {ideal }} / \mathrm{eV}$ & $\begin{array}{l}G_{\text {excess }} \\
/ \mathrm{eV}\end{array}$ & $x_{Y}(\%)$ & $\begin{array}{l}\bar{G}_{\text {excess }}(J \\
/ \mathrm{mol})\end{array}$ \\
\hline \multirow{6}{*}{$723 \mathrm{~K}$} & $\mathrm{LiCl}-\mathrm{KCl}-1 \mathrm{YCl}_{3}$ & -1804.7606 & -1803.8782 & -0.882 & 0.4975 & -423.5670 \\
\hline & $\mathrm{LiCl}-\mathrm{KCl}-2 \mathrm{YCl}_{3}$ & -1850.7802 & -1848.9854 & -1.795 & 0.9901 & -857.2989 \\
\hline & $\mathrm{LiCl}-\mathrm{KCl}-3 \mathrm{YCl}_{3}$ & -1896.5929 & -1894.0603 & -2.533 & 1.4778 & -1203.7118 \\
\hline & $\mathrm{LiCl}-\mathrm{KCl}-4 \mathrm{YCl}_{3}$ & -1942.3670 & -1939.1144 & -3.253 & 1.9608 & -1538.4003 \\
\hline & $\mathrm{LiCl}-\mathrm{KCl}-5 \mathrm{YCl}_{3}$ & -1988.1419 & -1984.1530 & -3.989 & 2.4390 & -1877.4345 \\
\hline & LiCl-KCl-6 $\mathrm{YCl}_{3}$ & -2033.9801 & -2029.1794 & -4.801 & 2.9126 & -2248.5198 \\
\hline \multirow{6}{*}{$773 \mathrm{~K}$} & $\mathrm{LiCl}-\mathrm{KCl}-1 \mathrm{YCl}_{3}$ & -1819.3650 & -1818.3960 & -0.969 & 0.4975 & -465.1852 \\
\hline & $\mathrm{LiCl}-\mathrm{KCl}-2 \mathrm{YCl}_{3}$ & -1865.2936 & -1863.6221 & -1.672 & 0.9901 & -798.3973 \\
\hline & $\mathrm{LiCl}-\mathrm{KCl}-3 \mathrm{YCl}_{3}$ & -1911.3322 & -1908.8138 & -2.518 & 1.4778 & -1196.9790 \\
\hline & LiCl-KCl-4 $\mathrm{YCl}_{3}$ & -1957.1849 & -1953.9831 & -3.202 & 1.9608 & -1514.3400 \\
\hline & $\mathrm{LiCl}-\mathrm{KCl}-5 \mathrm{YCl}_{3}$ & -2003.2109 & -1999.1360 & -4.075 & 2.4390 & -1917.9170 \\
\hline & LiCl-KCl-6 $\mathrm{YCl}_{3}$ & -2049.0048 & -2044.2758 & -4.729 & 2.9126 & -2214.9702 \\
\hline
\end{tabular}

The data of mole fraction and molar excess Gibbs free energy were used to fit a curve which can be seen in Figure 7 and the activity coefficients were also calculated by equation (10), the plot of activity coefficients with mole fractions is shown in Figure 8. The results of our calculated activity coefficients of $\mathrm{YCl}_{3}$ are compared with other literatures, it can be seen from Table 9 our work agrees quite well with others. 


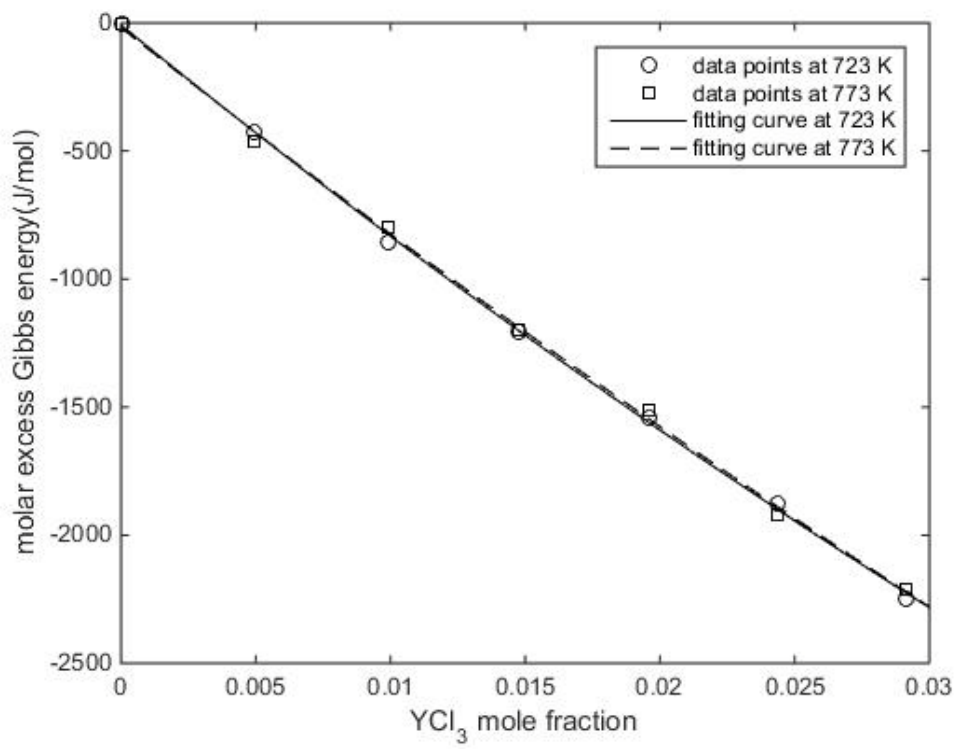

Figure 7. The fitting curve of molar excess Gibbs free energy to mole fraction of $\mathrm{YCl}_{3}$ in the solution

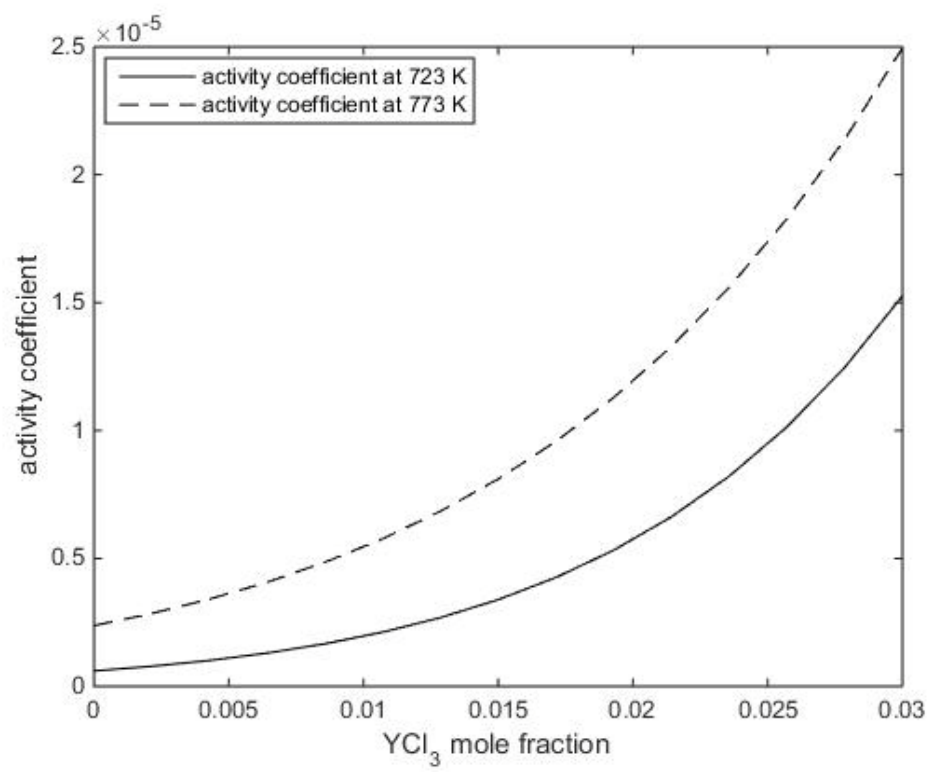

Figure 8. Activity coefficient of $\mathrm{YCl}_{3}$ in eutectic molten salt at the temperatures of $723 \mathrm{~K}$ and $773 \mathrm{~K}$

Table 9. Comparison between calculated activity coefficients of $\mathrm{YCl}_{3}$ and literature values

\begin{tabular}{|c|c|c|c|}
\hline Temperature & Mole fraction & Calculated activity coefficient $^{\mathrm{d}}$ & Literature value \\
\hline $723 \mathrm{~K}$ & Dilution & $0.6 \times 10^{-6} \sim 1.4 \times 10^{-6}$ & $2.34 \times 10^{-6}[11]$ \\
\hline
\end{tabular}




\begin{tabular}{|c|c|c|c|}
\hline & Dilution & & $2.40 \times 10^{-6}[64]$ \\
\cline { 2 - 2 } & Dilution & & $2.06 \times 10^{-6}[49]$ \\
\hline $773 \mathrm{~K}$ & Dilution & $2.4 \times 10^{-6} \sim 4.4 \times 10^{-6}$ & $5.36 \times 10^{-6}[11]$ \\
\hline
\end{tabular}

$\mathrm{d}$ : the calculated results corresponding to the mole fraction of $0-7.29 \times 10^{-3}$.

Apparent standard potential of $\mathrm{YCl}_{3}$ can be obtained through equation (11) after the value of activity coefficient has been calculated. What Figure 9 shows is the relationship between apparent standard potential and $\mathrm{YCl}_{3}$ mole fraction. The calculated apparent standard potential was compared with other literatures in Table 10 and it can be seen our calculated result is quite reasonable.

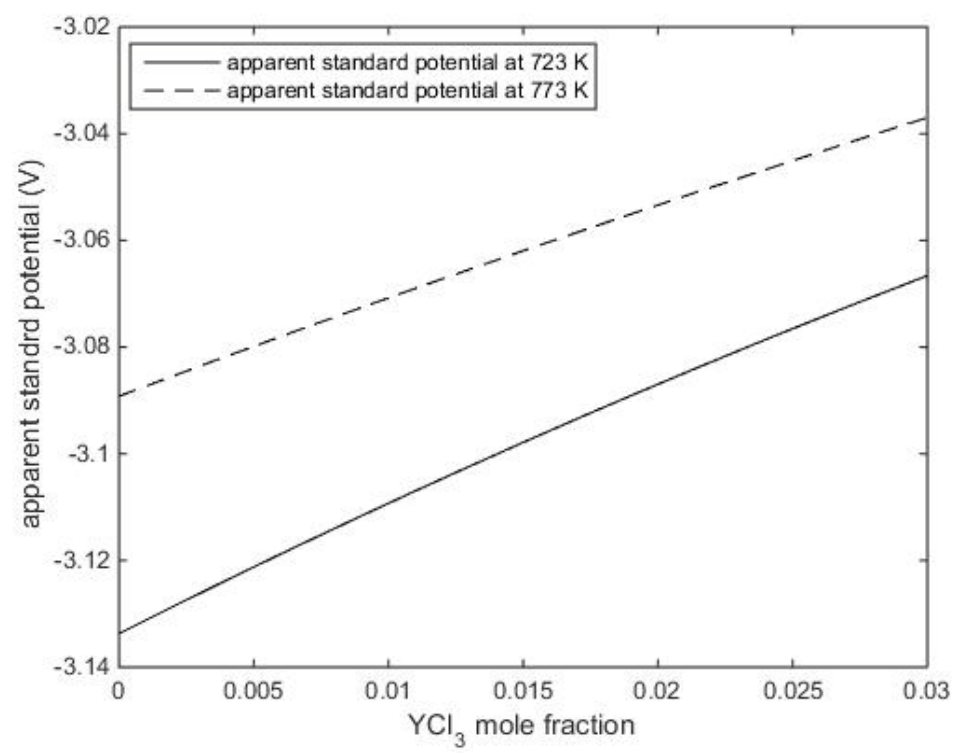

Figure 9. Apparent standard potential of $\mathrm{YCl}_{3}$ at the temperatures of $723 \mathrm{~K}$ and $773 \mathrm{~K}$

Table 10. Comparison between the calculated apparent standard potential of $\mathrm{YCl}_{3}$ and literature values

\begin{tabular}{|c|c|c|c|}
\hline Temperature & Mole fraction & Calculated results $(\mathrm{V})^{\mathrm{e}}$ & Literature value $(\mathrm{V})$ \\
\hline \multirow{3}{*}{$723 \mathrm{~K}$} & Dilution & \multirow{2}{*}{$-3.134 \sim-3.116$} & $-3.106[11]$ \\
\hline & Dilution & & $-3.108[49]$ \\
\hline & $1.21 \times 10^{-3}$ & -3.131 & $-3.126[61]$ \\
\hline $773 \mathrm{~K}$ & Dilution & $-3.089 \sim-3.076$ & $-3.071[11]$ \\
\hline
\end{tabular}

e: the calculated results corresponding to the mole fraction of $0-7.29 \times 10^{-3}$.

Just as what Figure 10 shows, self-diffusion coefficients and chemical diffusion coefficients were also calculated with different mole fractions of $\mathrm{YCl}_{3}$ at the temperatures of $723 \mathrm{~K}$ and 773 $\mathrm{K}$. The comparison in Table 11 shows our calculated chemical diffusion coefficients agree well with other literature values. 


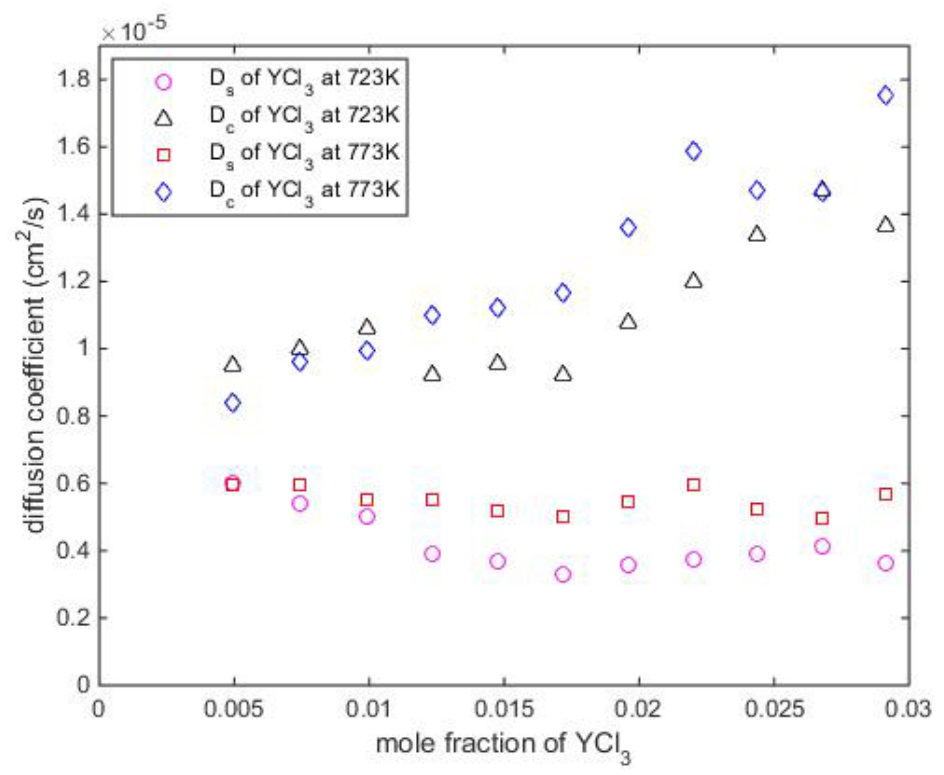

Figure 10. Self-diffusion coefficient and chemical diffusion coefficient of $\mathrm{YCl}_{3}$ at the temperatures of $723 \mathrm{~K}$ and $773 \mathrm{~K}$

Table 11. Comparison between calculated chemical diffusion coefficients of $\mathrm{YCl}_{3}$ and literature values

\begin{tabular}{|c|c|c|}
\hline Temperature & The range of $\mathrm{D}_{\mathrm{c}}\left(\mathrm{cm}^{2} / \mathrm{s}\right)^{\mathrm{f}}$ & Literature value $\left(\mathrm{cm}^{2} / \mathrm{s}\right)$ \\
\hline $723 \mathrm{~K}$ & $9.2 \times 10^{-6} \sim 14.7 \times 10^{-6}$ & $9.15 \times 10^{-6}[62]$ \\
\cline { 3 - 3 } & & $10 \pm 1 \times 10^{-6}[62]$ \\
\hline $773 \mathrm{~K}$ & $8.4 \times 10^{-6} \sim 17.5 \times 10^{-6}$ & $12.91 \times 10^{-6}[62]$ \\
\hline
\end{tabular}

$f:$ the range of $D_{c}$ corresponding to the mole fraction of 0.004975-0.029126.

\section{Scandium}

For $\mathrm{ScCl}_{3}$, the Gibbs free energy for the ideal solution and real solution, excess Gibbs free energy and molar excess Gibbs free energy of the systems of LiCl-KCl-n ScCl3 are presented in Table 12.

Table 12. The results of total Gibbs free energy for ideal solution and real solution, excess Gibbs free energy and molar excess Gibbs free energy of $\mathrm{LiCl}-\mathrm{KCl}-\mathrm{ScCl}_{3}$ mixture

\begin{tabular}{|c|c|c|c|c|c|c|}
\hline \multirow{2}{*}{ Temperature } & Component & $G_{\text {real }} / \mathrm{eV}$ & $G_{\text {ideal }} / \mathrm{eV}$ & $\begin{array}{l}G_{\text {excess }} \\
/ \mathrm{eV}\end{array}$ & $x_{\text {La }}(\%)$ & $\begin{array}{l}\bar{G}_{\text {excess }}(\mathrm{J} \\
/ \mathrm{mol})\end{array}$ \\
\hline \multirow{3}{*}{$723 \mathrm{~K}$} & $\mathrm{LiCl}-\mathrm{KCl}-1 \mathrm{ScCl}_{3}$ & -1807.0520 & -1805.8616 & -1.190 & 0.4975 & -571.4470 \\
\cline { 2 - 7 } & $\mathrm{LiCl}-\mathrm{KCl}-2 \mathrm{ScCl}_{3}$ & -1855.1587 & -1852.9521 & -2.207 & 0.9901 & -1053.9455 \\
\cline { 2 - 7 } & $\mathrm{LiCl}^{\mathrm{K} C l}-3 \mathrm{ScCl}_{3}$ & -1903.1243 & -1900.0104 & -3.114 & 1.4778 & -1480.0146 \\
\hline
\end{tabular}




\begin{tabular}{|c|c|c|c|c|c|c|}
\hline & LiCl-KCl-4 ScCl 3 & -1951.2471 & -1947.0478 & -4.199 & 1.9608 & -1986.1124 \\
\hline & LiCl-KCl-5 $\mathrm{ScCl}_{3}$ & -1999.2335 & -1994.0698 & -5.164 & 2.4390 & -2430.3130 \\
\hline & LiCl-KCl-6 $\mathrm{ScCl}_{3}$ & -2047.3144 & -2041.0796 & -6.235 & 2.9126 & -2920.2349 \\
\hline \multirow{6}{*}{$773 \mathrm{~K}$} & LiCl-KCl-1 $\mathrm{ScCl}_{3}$ & -1821.5464 & -1820.3851 & -1.161 & 0.4975 & -557.4775 \\
\hline & LiCl-KCl-2 $\mathrm{ScCl}_{3}$ & -1869.8180 & -1867.6004 & -2.218 & 0.9901 & -1059.2512 \\
\hline & $\mathrm{LiCl}-\mathrm{KCl}-3 \mathrm{ScCl}_{3}$ & -1917.9945 & -1914.7812 & -3.213 & 1.4778 & -1527.2678 \\
\hline & $\mathrm{LiCl}-\mathrm{KCl}-4 \mathrm{ScCl}_{3}$ & -1966.0927 & -1961.9396 & -4.153 & 1.9608 & -1964.2790 \\
\hline & LiCl-KCl-5 $\mathrm{ScCl}_{3}$ & -2014.3452 & -2009.0816 & -5.264 & 2.4390 & -2477.3489 \\
\hline & LiCl-KCl-6 $\mathrm{ScCl}_{3}$ & -2062.2667 & -2056.2105 & -6.056 & 2.9126 & -2836.5963 \\
\hline
\end{tabular}

The curve fitted by these data of mole fraction of $\mathrm{ScCl}_{3}$ and molar excess Gibbs free energy is shown in Figure 11 and it can be seen the fitting result is quite good. Figure 12 shows the values of activity coefficients of $\mathrm{ScCl}_{3}$ at different concentrations for the temperatures of $723 \mathrm{~K}$ and 773 $\mathrm{K}$. The calculated activity coefficients of $\mathrm{ScCl}_{3}$ were compared with other literatures in Table 13 and present a good agreement.

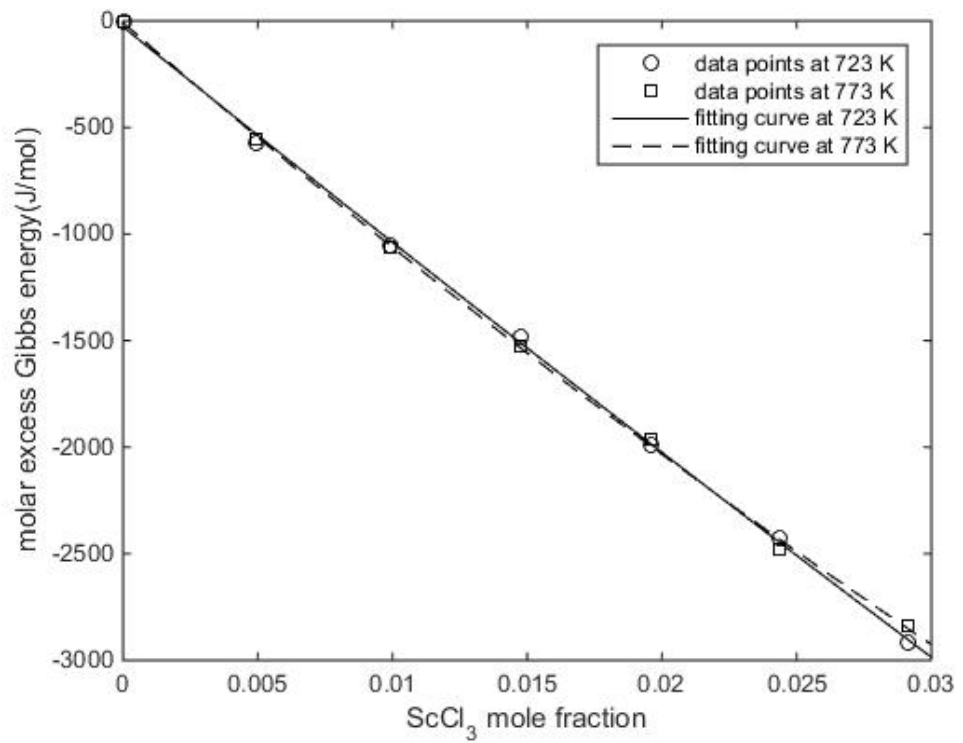

Figure 11. The fitting curve of molar excess Gibbs free energy to mole fraction of $\mathrm{ScCl}_{3}$ in the solution 


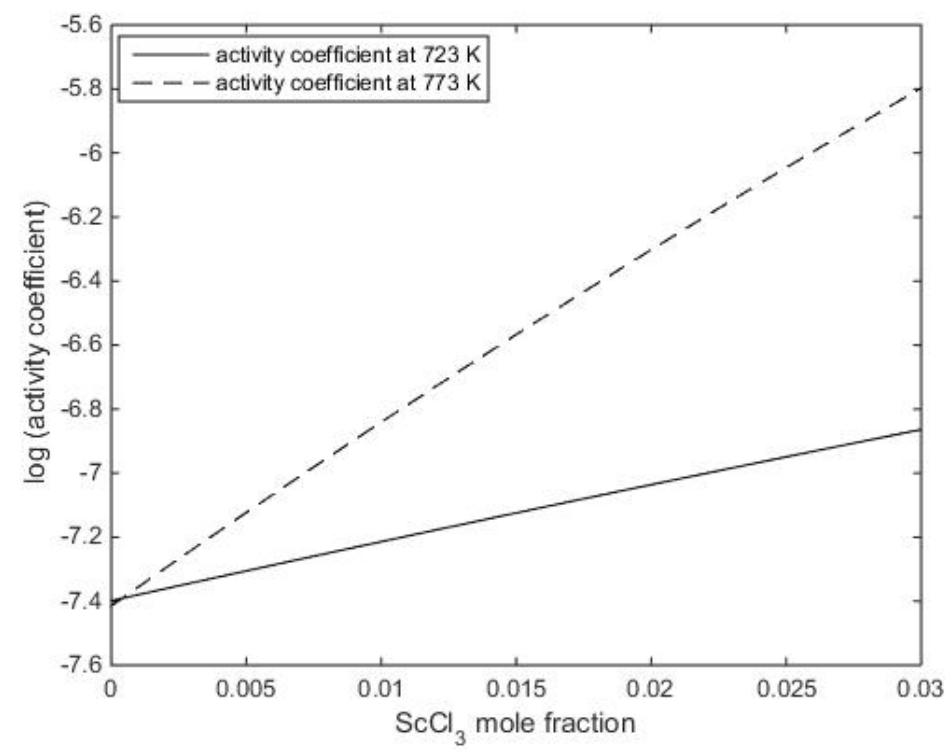

Figure 12. Activity coefficient of $\mathrm{ScCl}_{3}$ in eutectic molten salt at the temperatures of $723 \mathrm{~K}$ and $773 \mathrm{~K}$

Table 13. Comparison between the calculated activity coefficients of $\mathrm{ScCl}_{3}$ and literature values

\begin{tabular}{|c|c|c|c|}
\hline Temperature & Mole fraction & Calculated activity coefficient & Literature value \\
\hline $723 \mathrm{~K}$ & $4.26 \times 10^{-3}$ & $0.5 \times 10^{-7}$ & $1.000 \times 10^{-7}[51]$ \\
\hline $773 \mathrm{~K}$ & $4.26 \times 10^{-3}$ & $0.7 \times 10^{-7}$ & $3.981 \times 10^{-7}[51]$ \\
\hline
\end{tabular}

Figure 13 presents that apparent standard potential of $\mathrm{ScCl}_{3}$ increases with the mole fraction at the temperatures of $723 \mathrm{~K}$ and $773 \mathrm{~K}$ and Table 14 shows that our calculated results of $\mathrm{ScCl}_{3}$ are quite reasonable when comparing with other literature values. 


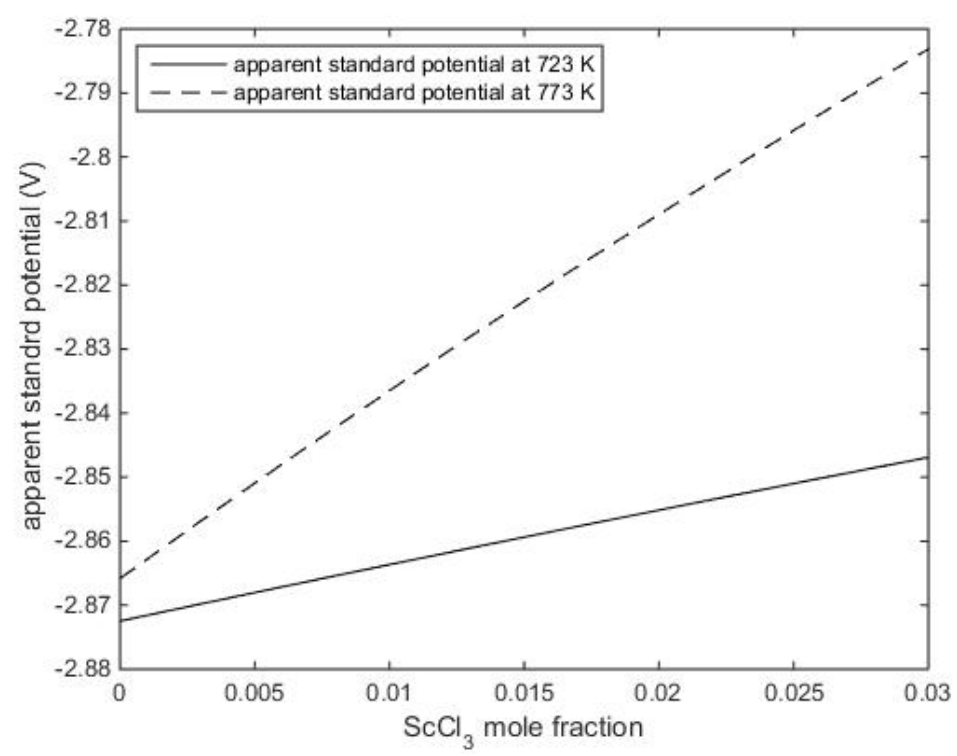

Figure 13. Apparent standard potential of $\mathrm{ScCl}_{3}$ at the temperatures of $723 \mathrm{~K}$ and $773 \mathrm{~K}$

Table 14. Comparison between the calculated apparent standard potential of $\mathrm{ScCl}_{3}$ and literature values

\begin{tabular}{|c|c|c|c|}
\hline Temperature & Mole fraction & Calculated results (V) & Literature value (V) \\
\hline $723 \mathrm{~K}$ & $4.26 \times 10^{-3}$ & -2.869 & $-2.852 \pm 0.009[51]$ \\
\hline $773 \mathrm{~K}$ & $4.26 \times 10^{-3}$ & -2.853 & $-2.816 \pm 0.012[51]$ \\
\hline
\end{tabular}

The calculated chemical diffusion coefficients and self-diffusion coefficients of $\mathrm{ScCl}_{3}$ were also obtained and shown in Figure 14. The comparisons in Table 15 show our calculated results are consistent with other literature values. 


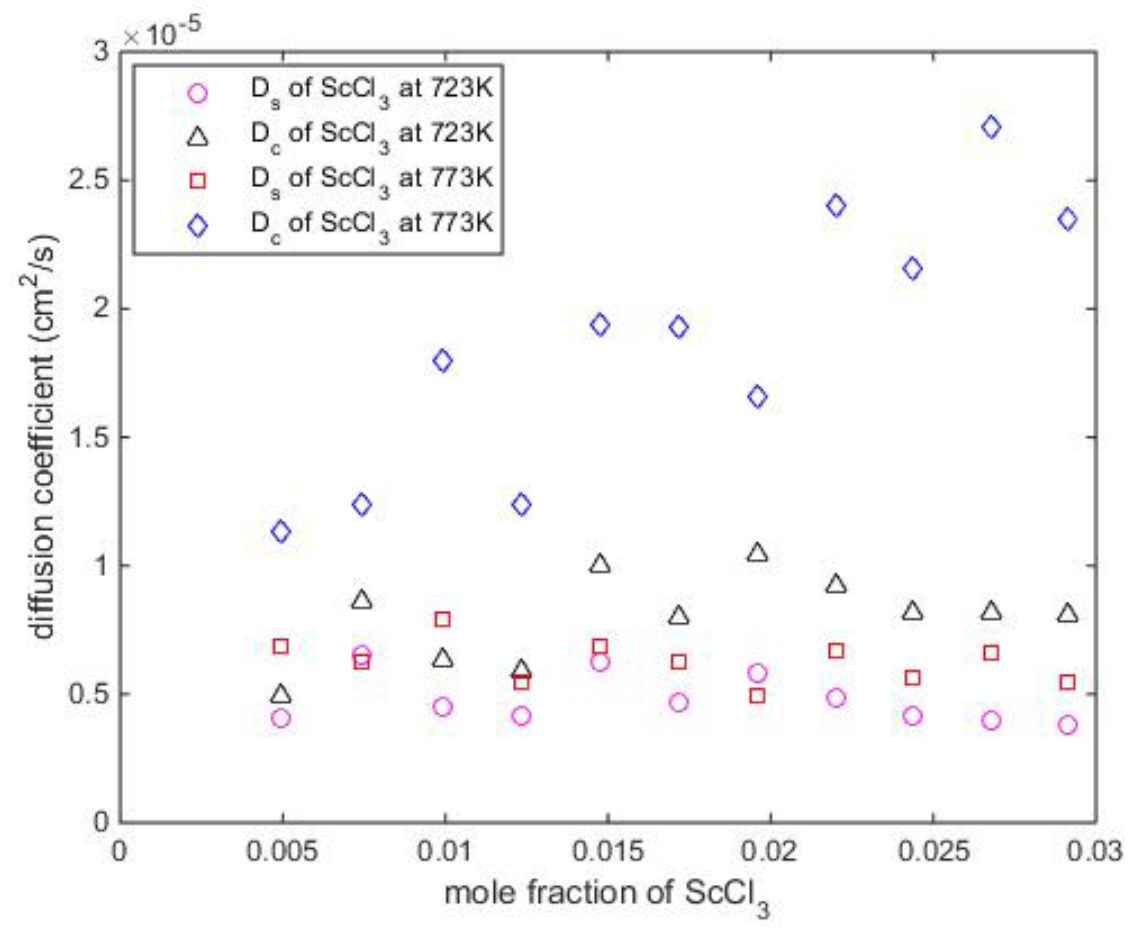

Figure 14. Self-diffusion coefficient and chemical diffusion coefficient of $\mathrm{ScCl}_{3}$ at the temperatures of $723 \mathrm{~K}$ and $773 \mathrm{~K}$

Table 15. Comparison between the calculated chemical diffusion coefficients and literature values

\begin{tabular}{|c|c|c|}
\hline Temperature & The range of $\mathrm{D}_{\mathrm{c}}\left(\mathrm{cm}^{2} / \mathrm{s}\right)^{\mathrm{g}}$ & Literature value $\left(\mathrm{cm}^{2} / \mathrm{s}\right)$ \\
\hline $723 \mathrm{~K}$ & $4.9 \times 10^{-6} \sim 10.5 \times 10^{-6}$ & $3.0363 \times 10^{-6} \sim 11.079 \times 10^{-6}[51]$ \\
\hline $773 \mathrm{~K}$ & $1.1 \times 10^{-5} \sim 2.7 \times 10^{-5}$ & $0.4675 \times 10^{-5} \sim 1.6356 \times 10^{-5}[51]$ \\
\hline
\end{tabular}

$\mathrm{g}$ : the range of $\mathrm{D}_{\mathrm{c}}$ corresponding to the mole fraction of $0.004975-0.029126$.

\section{Terbium}

For $\mathrm{TbCl}_{3}$, the total Gibbs free energy for the ideal solution and real solution, excess Gibbs free energy and molar excess Gibbs free energy are shown in Table 16.

Table 16. The results of total Gibbs free energy for ideal solution and real solution, excess Gibbs free energy and molar excess Gibbs free energy of $\mathrm{LiCl}-\mathrm{KCl}-\mathrm{TbCl}_{3}$ mixture

\begin{tabular}{|c|c|c|c|c|c|c|}
\hline Temperature & Component & $G_{\text {real }} / \mathrm{eV}$ & $G_{\text {ideal }} / \mathrm{eV}$ & $\begin{array}{l}G_{\text {excess }} \\
/ \mathrm{eV}\end{array}$ & $x_{\mathrm{La}}(\%)$ & $\begin{array}{l}\bar{G}_{\text {excess }}(\mathrm{J} \\
/ \mathrm{mol})\end{array}$ \\
\hline \multirow{3}{*}{$723 \mathrm{~K}$} & $\mathrm{LiCl}-\mathrm{KCl}-1 \mathrm{TbCl}_{3}$ & -1804.9711 & -1804.2051 & -0.766 & 0.4975 & -367.7047 \\
\cline { 2 - 7 } & $\mathrm{LiCl}-\mathrm{KCl}-2 \mathrm{TbCl}_{3}$ & -1850.9912 & -1849.6392 & -1.352 & 0.9901 & -645.8076 \\
\cline { 2 - 7 } & $\mathrm{LiCl}-\mathrm{KCl}-3 \mathrm{TbCl}_{3}$ & -1896.9228 & -1895.0410 & -1.882 & 1.4778 & -894.3967 \\
\hline
\end{tabular}




\begin{tabular}{|c|c|c|c|c|c|c|}
\hline & LiCl-KCl-4 $\mathrm{TbCl}_{3}$ & -1942.9174 & -1940.4220 & -2.495 & 1.9608 & -1180.2419 \\
\hline & LiCl-KCl-5 $\mathrm{TbCl}_{3}$ & -1988.9049 & -1985.7875 & -3.117 & 2.4390 & -1467.2286 \\
\hline & LiCl-KCl-6 $\mathrm{TbCl}_{3}$ & -2034.7879 & -2031.1408 & -3.647 & 2.9126 & -1708.2251 \\
\hline \multirow{6}{*}{$773 \mathrm{~K}$} & LiCl-KCl-1 $\mathrm{TbCl}_{3}$ & -1819.5834 & -1818.6976 & -0.886 & 0.4975 & -425.1719 \\
\hline & $\mathrm{LiCl}-\mathrm{KCl}-2 \mathrm{TbCl}_{3}$ & -1865.5644 & -1864.2255 & -1.339 & 0.9901 & -639.5128 \\
\hline & LiCl-KCl-3 $\mathrm{TbCl}_{3}$ & -1911.6961 & -1909.7188 & -1.977 & 1.4778 & -939.8195 \\
\hline & $\mathrm{LiCl}-\mathrm{KCl}-4 \mathrm{TbCl}_{3}$ & -1957.7596 & -1955.1898 & -2.570 & 1.9608 & -1215.4260 \\
\hline & LiCl-KCl-5 $\mathrm{TbCl}_{3}$ & -2003.8904 & -2000.6444 & -3.246 & 2.4390 & -1527.7714 \\
\hline & LiCl-KCl-6 $\mathrm{TbCl}_{3}$ & -2049.9205 & -2046.0858 & -3.835 & 2.9126 & -1796.0615 \\
\hline
\end{tabular}

The fitting curves of the excess Gibbs free energy as a function of the mole fraction are given in Figure 15. It shows the fitting result is pretty well. What Figure 16 shows are the values of activity coefficients of $\mathrm{TbCl}_{3}$ at different mole fractions for the temperatures of $723 \mathrm{~K}$ and $773 \mathrm{~K}$.

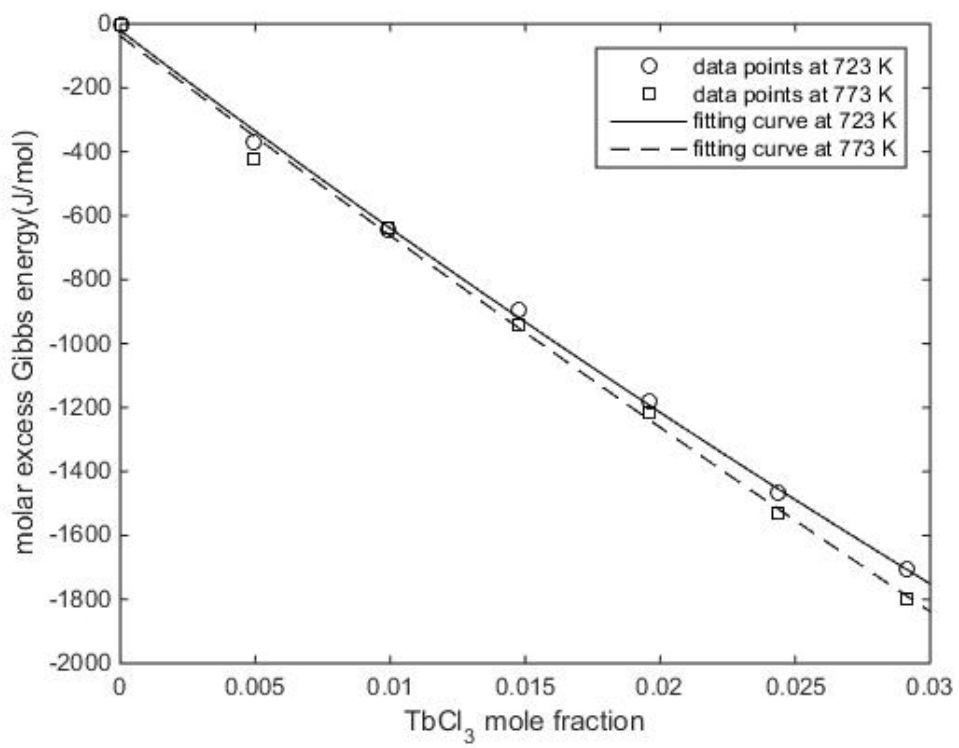

Figure 15. The fitting curve of molar excess Gibbs free energy to mole fraction of $\mathrm{TbCl}_{3}$ in the solution 


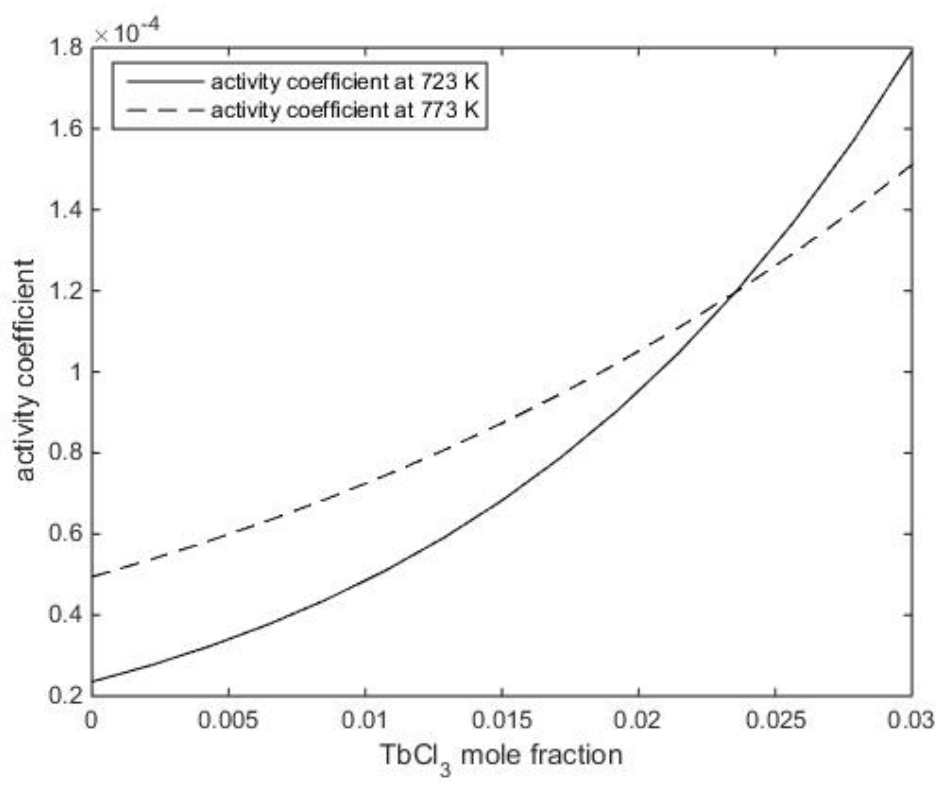

Figure 16. Activity coefficient of $\mathrm{TbCl}_{3}$ in eutectic molten salt at the temperature of $723 \mathrm{~K}$ and $773 \mathrm{~K}$

Table 17. Comparison between the calculated activity coefficients of $\mathrm{TbCl}_{3}$ and literature values

\begin{tabular}{|c|c|c|c|}
\hline Temperature & Mole fraction & Calculated activity coefficient & Literature value \\
\hline $723 \mathrm{~K}$ & $3.68 \times 10^{-3}$ & $3.1 \times 10^{-5}$ & $1.7378 \times 10^{-5}[53]$ \\
\hline $773 \mathrm{~K}$ & $3.68 \times 10^{-3}$ & $5.7 \times 10^{-5}$ & $2.4547 \times 10^{-5}[53]$ \\
\hline
\end{tabular}

As Figure 17 shows, the apparent standard potential of $\mathrm{TbCl}_{3}$ at different concentrations were calculated and shown. The comparisons with the literature values are presented in Table 18 and it can be seen our calculated apparent standard potential is quite good. 


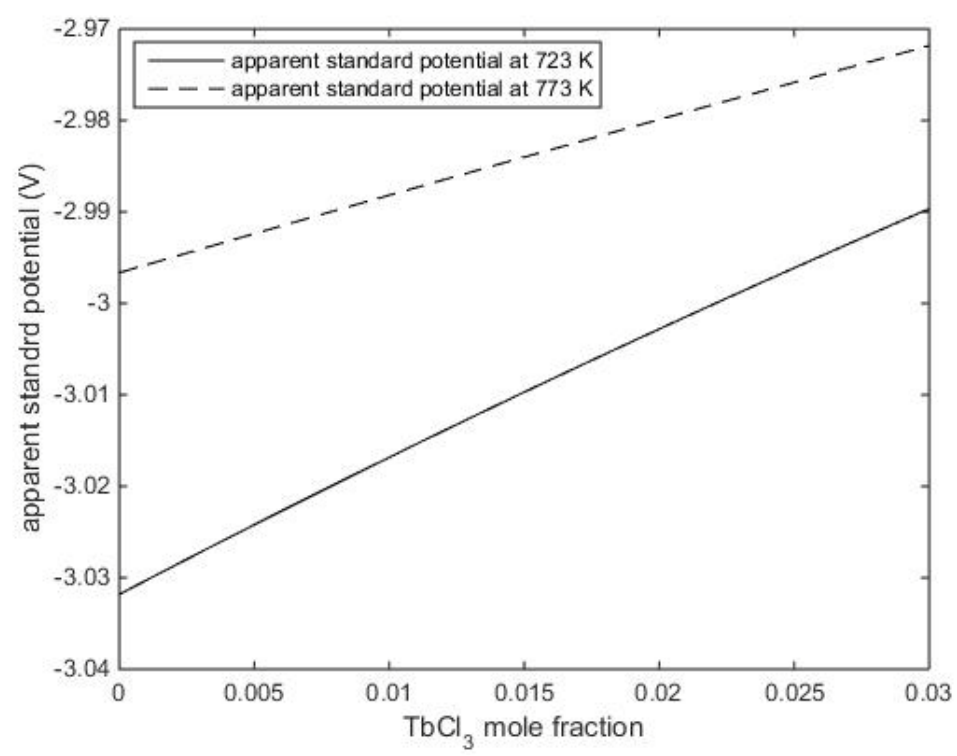

Figure 17. Apparent standard potential of $\mathrm{TbCl}_{3}$ at the temperatures of $723 \mathrm{~K}$ and $773 \mathrm{~K}$

Table 18. Comparison between the calculated apparent standard potential of $\mathrm{TbCl}_{3}$ and literature values

\begin{tabular}{|c|c|c|c|}
\hline Temperature & Mole fraction & Calculated results (V) & Literature value (V) \\
\hline $723 \mathrm{~K}$ & $3.68 \times 10^{-3}$ & -3.026 & $-3.038[53]$ \\
\hline $773 \mathrm{~K}$ & $3.68 \times 10^{-3}$ & -2.944 & $-3.012[53]$ \\
\hline
\end{tabular}

The chemical diffusion coefficients and self-diffusion coefficients of $\mathrm{TbCl}_{3}$ at several different mole fractions were calculated and shown in Figure 18. The comparison results are shown in Table 19, it can be seen that our calculated chemical diffusion coefficients agree quite well with other literature values. 


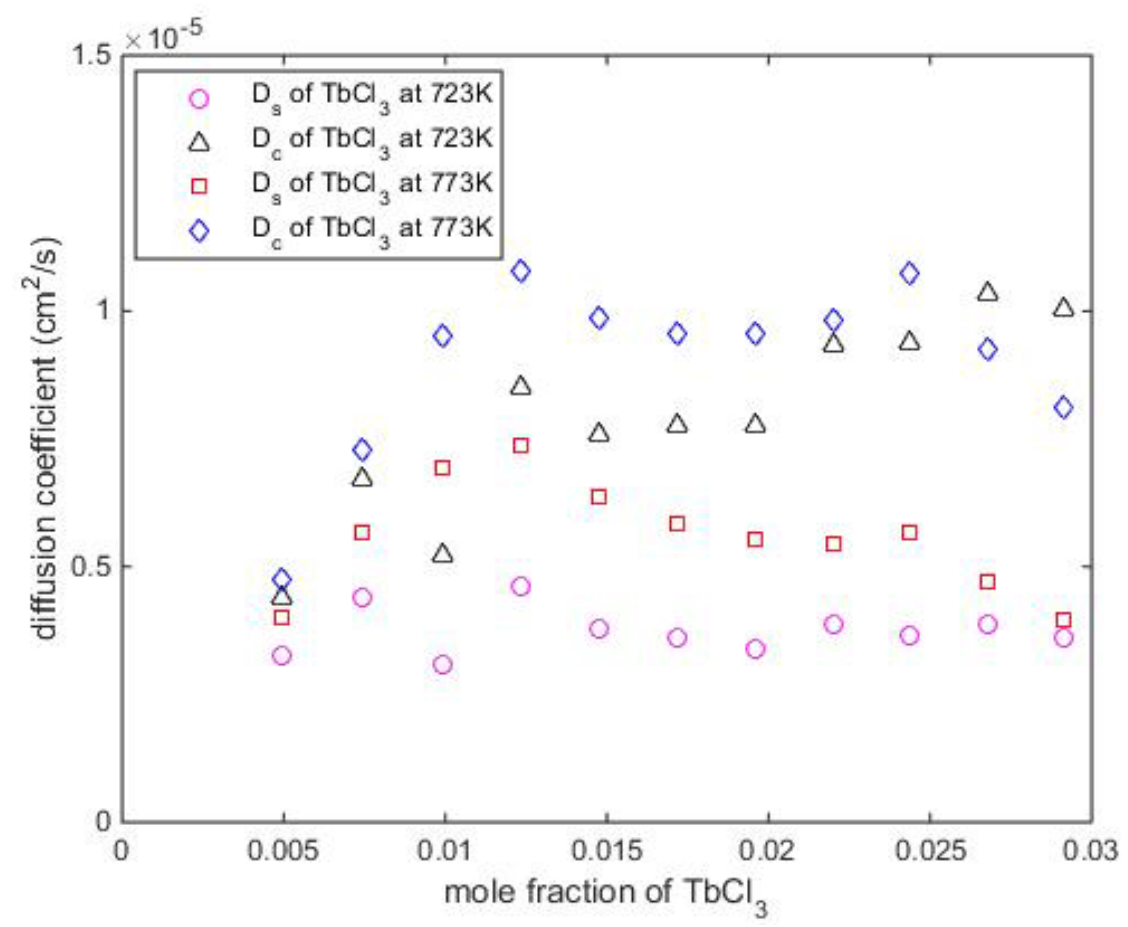

Figure 18. Self-diffusion coefficient and chemical diffusion coefficient of $\mathrm{TbCl}_{3}$ at the temperatures of $723 \mathrm{~K}$ and $773 \mathrm{~K}$

Table 19. Comparison between the calculated chemical diffusion coefficients of $\mathrm{TbCl}_{3}$ and literature values

\begin{tabular}{|c|c|c|}
\hline Temperature & The range of $\mathrm{D}_{\mathrm{c}}\left(\mathrm{cm}^{2} / \mathrm{s}\right)^{\mathrm{h}}$ & Literature value $\left(\mathrm{cm}^{2} / \mathrm{s}\right)$ \\
\hline $723 \mathrm{~K}$ & $4.7 \times 10^{-6} \sim 10.3 \times 10^{-6}$ & $3.7653 \times 10^{-6} \sim 10.468 \times 10^{-6}[53]$ \\
\hline $773 \mathrm{~K}$ & $4.4 \times 10^{-6} \sim 10.7 \times 10^{-6}$ & $5.4836 \times 10^{-6} \sim 14.745 \times 10^{-6}[53]$ \\
\hline
\end{tabular}

$\mathrm{h}$ : the range of $\mathrm{D}_{\mathrm{c}}$ corresponding to the mole fraction of 0.004975-0.029126.

Refer all the results above, a bunch of new features of these thermodynamic data are established, particularly in terms of the concentration. Figure 4, Figure 8, Figure 12 and Figure 16 show that the activity coefficients of $\mathrm{RE}^{3+}$ increase with the mole fraction. The value could increase by 3 to 40 times from dilution to $3 a t \%$. The increase rate in low concentration is slow while it is relatively larger at high concentration. This phenomenon may be due to the structure transition with the concentration. Excess Gibbs energy or the activity coefficient in an A-B binary system is because of the differences of interaction between A-A, A-B, and B-B pairs $[65,66]$. Thus they are sensitive to the atoms' surrounding neighbors. At the pretty dilute solution, solute's neighbor change little with new solute added however the effect could be significant when the concentration is higher but not too high. It also should be noticed the values of activity coefficients of $\mathrm{Y}^{3+}, \mathrm{Sc}^{3+}$ at the temperature of $773 \mathrm{~K}$ are larger than that at the temperature of 723 $\mathrm{K}$, however, the values of activity coefficients of $\mathrm{La}^{3+}$ at the temperature of $723 \mathrm{~K}$ are larger, which is consistent with the fitting equation reported in the temperature range of $650 \mathrm{~K}$ to $870 \mathrm{~K}$ 
[11]. The most interesting thing is the activity coefficient of $\mathrm{Tb}^{3+}$ at $773 \mathrm{~K}$ is larger than that at $723 \mathrm{~K}$ for low mole fraction while the activity coefficient at $723 \mathrm{~K}$ is larger when the mole fraction is higher than around 0.0235 . Some structure changes may happen here and more investigation and studies are needed to fully understand it. As the concentration of $\mathrm{RECl}_{3}$ is relative high at the beginning and then decrease because of the deposition of RE on the solid electrode in the real pyroprocessing, the investigation of activity coefficients at different concentrations will contribute greatly in the future industry development for pyroprocessing.

Apparent standard potential of $\mathrm{La}^{3+}, \mathrm{Y}^{3+}, \mathrm{Sc}^{3+}$ and $\mathrm{Tb}^{3+}$ with mole fraction are shown in Figure 5, Figure 9, Figure 13 and Figure 17, it can be seen that the apparent standard potential of $\mathrm{RE}^{3+}$ increase with the mole fraction and the apparent standard potential at the temperature $773 \mathrm{~K}$ is a little larger than that at the temperature of $723 \mathrm{~K}$ even for the $\mathrm{Tb}^{3+}$. But the difference among the apparent standard potential at different concentrations is really small while it is pretty large for activity coefficient.

From what Figure 6, Figure 10, Figure 14 and Figure 18 presents, there is no solid dependence but only some fluctuations found about self-diffusion coefficients with respect to concentration. While it should be noticed that the Chemical diffusion coefficients show dependence on the mole fractions and it seems like that with the increase of mole fraction of $\mathrm{RECl}_{3}$, chemical diffusion coefficients of $\mathrm{RECl}_{3}$ increase initially and then decrease even though in a limited range. Moreover, our calculated results show that the chemical diffusion coefficients and selfdiffusion coefficients of $\mathrm{RECl}_{3}$ at $773 \mathrm{~K}$ are larger than that at the temperature of $723 \mathrm{~K}$.

\section{Discussion}

As mentioned above, researchers mainly focus on the investigation of thermodynamic properties at dilution. Generally, correlations are only reported in terms of temperature [11], which are the values applied in model development as well $[13,14]$. This paper provides a pretty comprehensive insight to the concentration dependence of basic thermodynamic data for the RE in melt, which was rarely reported before. These findings will complicate the calculation in application but may result in more accurate results. For example, without considering the over potential, potential of a solid electrode when $\mathrm{RE}^{3+}$ deposits on it can be expressed by Nernst equation

$$
\mathrm{E}=E^{0}+\frac{R T}{3 F} \ln x_{R E^{3+}} \gamma_{R E^{3+}}
$$

When the mole fraction of $\mathrm{RE}^{3+}$ decreases with deposition, the potential should also decrease following a linear relationship with $\ln x_{R E^{3+}}$ according to previous study. However, now it is known that potential will have a larger decreasing rate due to the change of activity coefficient. The distribution factor derived from the potential will also be affected by the property. 
Additionally, the diffusion equation is no longer a linear one because of the concentration dependence of diffusion coefficient, which can be stood for by the distance at non-homogeneous solution. These modifications will predict the performance and output of pyroprocessing more accurately and guide the design of pyroprocessing device.

\section{Summary and conclusion}

In the present paper, thermodynamic and transport properties of Lanthanum, Yttrium, Scandium, and Terbium were investigated by the method of molecular dynamics simulation. The calculation of activity coefficients, apparent standard potentials and diffusion coefficients at different concentrations and temperatures can help us identify the effects of concentration and temperature on thermodynamic properties. The comparison between our calculated results and literature values indicates our modelling has a relative high accuracy. This study contributes significantly to the investigation of thermodynamic properties since all of these properties are calculated at different concentrations while most of other available studies are focused on the dilution.

It was found that the activity coefficient and apparent standard potential strongly depend on the element concentration and the relationships between them are positive correlations. However, it seems that the chemical diffusion coefficients are slightly depend on the concentrations although it increases for lower concentrations and then decreases slightly when the concentration of $\mathrm{RECl}_{3}$ in eutectic molten salt is high enough. The interesting result is that there is no big change in the self-diffusion coefficient with the increase of concentration and it almost keeps stable.

Temperature also plays an important role in the thermodynamic properties of Lanthanum, Yttrium, Scandium and Terbium in eutectic molten salt. This result is same to the previous experimental measurements for diluted molten salt. However, the effects of temperature on the activity coefficient can be different for different elements and the same element at different concentrations. This study indicates that activity coefficients of $\mathrm{Y}^{3+}$ and $\mathrm{Sc}^{3+}$ at the temperature of $773 \mathrm{~K}$ are larger than that at the temperature of $723 \mathrm{~K}^{3}$ while $\mathrm{La}^{3+}$ appears in the opposite way. It should be noticed that activity coefficient of $\mathrm{Tb}^{3+}$ at $773 \mathrm{~K}$ is larger than that at $723 \mathrm{~K}$ for a low mole fractions while the activity coefficient at $723 \mathrm{~K}$ is larger when the mole fraction is higher than around 0.0235 . The apparent standard potential at $773 \mathrm{~K}$ is less negative than that at temperature of $773 \mathrm{~K}$ for $\mathrm{La}^{3+}, \mathrm{Y}^{3+}, \mathrm{Sc}^{3+}$ and $\mathrm{Tb}^{3+}$. Our calculated results also indicate diffusion coefficient at $773 \mathrm{~K}$ is larger than that at $723 \mathrm{~K}$ although there are some points which do not satisfy. The activity coefficients of these four different elements are also compared which can be seen in Figure 19 and Figure 20, it shows activity coefficient of $\mathrm{LaCl}_{3}$ is the largest while that of $\mathrm{ScCl}_{3}$ is the smallest. 


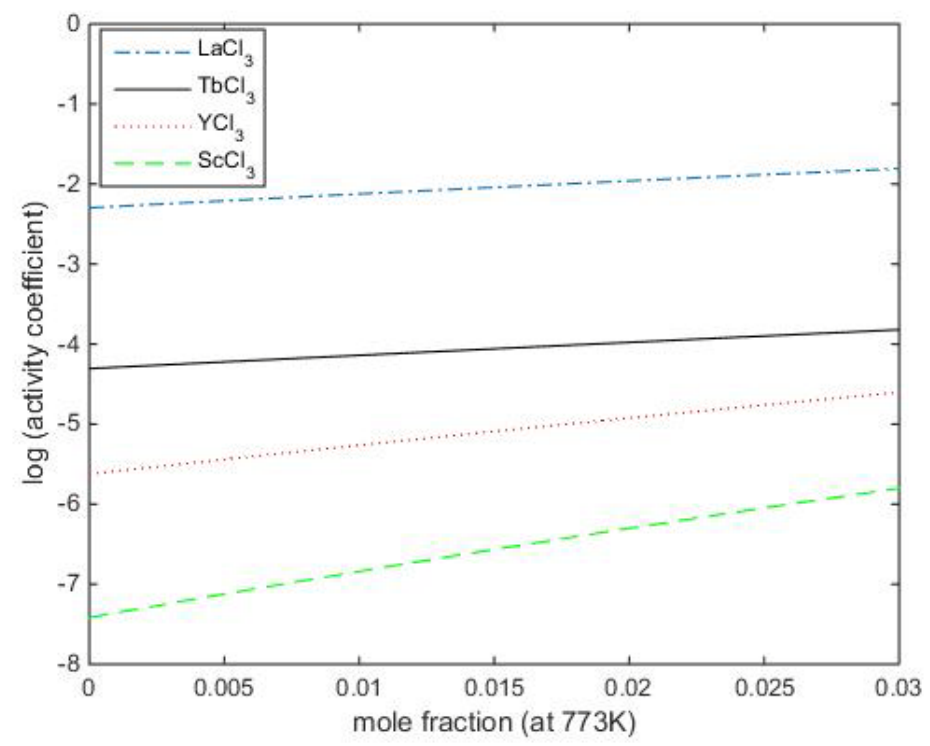

Figure 19. Activity coefficients of $\mathrm{LaCl}_{3}, \mathrm{TbCl}_{3}, \mathrm{YCl}_{3}$ and $\mathrm{ScCl}_{3}$ in eutectic molten salt at the temperature of $773 \mathrm{~K}$

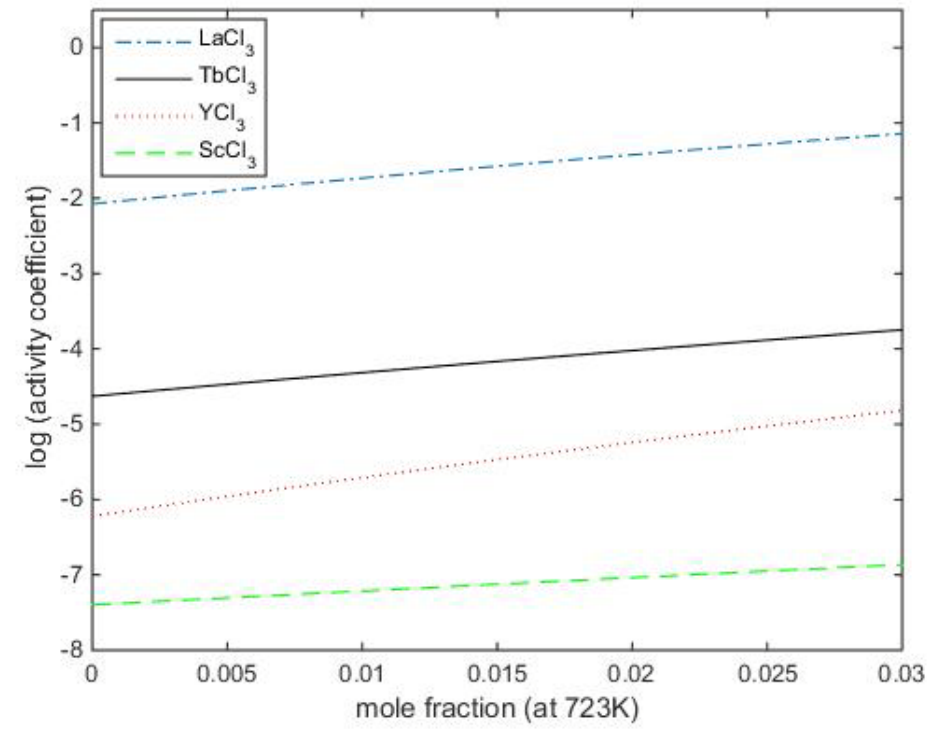

Figure 20. Activity coefficients of $\mathrm{LaCl}_{3}, \mathrm{TbCl}_{3}, \mathrm{YCl}_{3}, \mathrm{ScCl}_{3}$ in eutectic molten salt at the temperature of $723 \mathrm{~K}$

The present study is a pioneering work focusing on the concentration dependence of thermodynamic properties. It fills the gap between the existing data for only dilution and practical demand for high concentration solution. These findings will push us to reconsider the equations and correlations established before and help to optimize the electrorefining device.

\section{Acknowledgements}


This research has been performed using funding received from the DOE Office of Nuclear Energy's Nuclear Energy University Programs (Project 13-4908, PI: Prof. Jinsuo Zhang, Co-PI: Prof. Supathorn Phongikaroon ), and is supported in part by an allocation of computing time from the Ohio Supercomputer Center. 


\section{References}

[1] Salanne, Mathieu, et al. "Calculation of activities of ions in molten salts with potential application to the pyroprocessing of nuclear waste." The Journal of Physical Chemistry B 112.4 (2008): 1177-1183.

[2] Nash, Kenneth L., et al. Significance of the nuclear fuel cycle in the 21st century. No. PNNLSA-45672. Pacific Northwest National Laboratory (PNNL), Richland, WA (US), 2006.

[3] Chamelot, Pierre, et al. "Feasibility of the electrochemical way in molten fluorides for separating thorium and lanthanides and extracting lanthanides from the solvent." Journal of nuclear materials 360.1 (2007): 64-74.

[4] Griffiths, Trevor R., et al. "Reprocessing spent nuclear fuel using molten carbonates and subsequent precipitation of rare earth fission products using phosphate." Journal of alloys and compounds 418.1 (2006): 116-121.

[5] Inoue, Tadashi. "Actinide recycling by pyro-process with metal fuel FBR for future nuclear fuel cycle system." Progress in Nuclear Energy 40.3 (2002): 547-554.

[6] Zhou, Wentao, and Jinsuo Zhang. "Direct Calculation of Concentration-Dependent Activity Coefficient of $\mathrm{UCl}_{3}$ in Molten LiCl-KCl." Journal of The Electrochemical Society 162.10 (2015): E199-E204.

[7] Iizuka, Masatoshi, et al. "Behavior of plutonium and americium at liquid cadmium cathode in molten LiCl-KCl electrolyte." Journal of nuclear materials 299.1 (2001): 32-42.

[8] Koyama, Tadafumi, et al. "An experimental study of molten salt electrorefining of uranium using solid iron cathode and liquid cadmium cathode for development of pyrometallurgical reprocessing." Journal of nuclear science and technology 34.4 (1997): 384-393.

[9] Chang, Yoon I. "The integral fast reactor." Nuclear Technology 88.2 (1989): 129-138.

[10] Laidler, J. J., et al. IFR fuel cycle-pyroprocess development. Argonne National Lab., 1992.

[11] Zhang, Jinsuo. "Electrochemistry of actinides and fission products in molten salts - Data review." Journal of Nuclear Materials 447.1 (2014): 271-284.

[12] Koyama, Tadafumi, et al. "An experimental study of molten salt electrorefining of uranium using solid iron cathode and liquid cadmium cathode for development of pyrometallurgical reprocessing." Journal of nuclear science and technology 34.4 (1997): 384-393.

[13] Zhang, Jinsuo. "Kinetic model for electrorefining, part I: Model development and validation." Progress in Nuclear Energy 70 (2014): 279-286.

[14] Kobayashi, Tsuguyuki, and Moriyasu Tokiwai. "Development of TRAIL, a simulation code for the molten salt electrorefining of spent nuclear fuel."Journal of alloys and compounds 197.1 (1993): 7-16.

[15] Sakamura, Y., et al. "Distribution behavior of plutonium and americium in $\mathrm{LiCl}-\mathrm{KCl}$ eutectic/liquid cadmium systems." Journal of Alloys and Compounds 321.1 (2001): 76-83.

[16] Sakamura, Y., et al. "Measurement of standard potentials of actinides (U, Np, Pu, Am) in $\mathrm{LiCl}-\mathrm{KCl}$ eutectic salt and separation of actinides from rare earths by electrorefining." Journal of alloys and compounds 271 (1998): 592-596.

[17] Ghosh, Suddhasattwa, et al. "Anodic dissolution of U, Zr and U-Zr alloy and convolution voltammetry of $\mathrm{Zr}^{4+} \mid \mathrm{Zr}^{2+}$ couple in molten $\mathrm{LiCl}-\mathrm{KCl}$ eutectic."Electrochimica Acta 56.24 (2011): 8204-8218. 
[ 18 ] Uozumi, Koichi, et al. "Electrochemical behaviors of uranium and plutonium at simultaneous recoveries into liquid cadmium cathodes." Journal of nuclear materials 325.1 (2004): 34-43.

[19] Sakamura, Y., et al. "Measurement of standard potentials of actinides (U, Np, Pu, Am) in $\mathrm{LiCl}-\mathrm{KCl}$ eutectic salt and separation of actinides from rare earths by electrorefining." Journal of alloys and compounds 271 (1998): 592-596.

[20] Masset, Patrick, et al. "Thermochemical properties of lanthanides ( $\mathrm{Ln}=\mathrm{La}, \mathrm{Nd})$ and actinides $(\mathrm{An}=\mathrm{U}, \mathrm{Np}, \mathrm{Pu}, \mathrm{Am})$ in the molten $\mathrm{LiCl}-\mathrm{KCl}$ eutectic." Journal of Nuclear Materials 344.1 (2005): 173-179.

[21] Fukasawa, Kazuhito, et al. "Thermodynamic properties of trivalent lanthanide and actinide ions in molten mixtures of LiCl and KCl." Journal of Nuclear Materials 424.1 (2012): 17-22.

[22] Bechtel, Tom B., and Truman S. Storvick. "Activity coefficients of actinide and rare-earth chlorides in molten $\mathrm{LiCl} / \mathrm{KCl}$ eutectic salt." Industrial \& engineering chemistry research 38.4 (1999): 1723-1728.

[23] Roy, J. J., et al. "Thermodynamic Properties of U, Np, Pu, and Am in Molten LiCl-KCl Eutectic and Liquid Cadmium." Journal of the Electrochemical Society143.8 (1996): 2487-2492. [24] Uranium transport to solid electrodes in pyrochemical reprocessing of nuclear fuel

[25] Kuznetsov, S. A., et al. "Determination of uranium and rare-earth metals separation coefficients in $\mathrm{LiCl}-\mathrm{KCl}$ melt by electrochemical transient techniques." Journal of nuclear materials 344.1 (2005): 169-172.

[26] Masset, Patrick, et al. "Electrochemistry of uranium in molten LiCl-KCl eutectic."Journal of the Electrochemical Society 152.6 (2005): A1109-A1115.

[27] Inman, D., et al. "Electrode reactions in molten salts: the uranium+ uranium trichloride system." Transactions of the Faraday Society 55 (1959): 1904-1914.

[28] MEASUREMEKT OF THE URANIUM-URANIUM (III) POTENTIAL IN LiCl-KCl EUTECTIC

[29] R. Hoover, M. Shaltry, Co-PI, S. Martin, K. Sridharan, and M. Simpson, "Electrochemical Studies and Analysis of Uranium Chloride in Molten LiCl-KCl Eutectic," 2013 The Minerals, Metals, and Materials Society Annual Meeting, San Antonio, TX, March 3-7, 2013

[30] Cipiti B B, Duran F A, Key B, et al. Modeling and design of integrated safeguards and security for an electrochemical reprocessing facility $[\mathrm{J}]$. Sandia National Labs, Albuquerque, 2012.

[31] Huggins, Maurice L., and Joseph E. Mayer. "Interatomic distances in crystals of the alkali halides." The Journal of Chemical Physics 1.9 (1933): 643-646.

[32] Tironi, Ilario G., and Wilfred F. Van Gunsteren. "A molecular dynamics simulation study of chloroform." Molecular Physics 83.2 (1994): 381-403.

[33] Adams, D. J., and I. R. McDonald. "Rigid-ion models of the interionic potential in the alkali halides." Journal of Physics C: Solid State Physics7.16 (1974): 2761.

[34] Okamoto, Yoshihiro, Fumiaki Kobayashi, and Toru Ogawa. "Structure and dynamic properties of molten uranium trichloride." Journal of alloys and compounds 271 (1998): 355-358. [35] Rodrigues, Pedro CR, and Fernando MS Silva Fernandes. "Phase diagrams of alkali halides using two interaction models: A molecular dynamics and free energy study." The Journal of chemical physics 126.2 (2007): 024503.

[36] Frenkel D, Smit B. From algorithms to applications[J]. 1996. 
[37] Rodrigues, Pedro CR, and Fernando MS Silva Fernandes. "Phase diagrams of alkali halides using two interaction models: A molecular dynamics and free energy study." The Journal of chemical physics 126.2 (2007): 024503.

[38] Allen M P, Tildesley D J. Computer simulation of liquids[M]. Oxford university press, 1989. [39] Croteau T, Patey G N. Structures and rearrangements of LiCl clusters[J]. The Journal of chemical physics, 2006, 124(24): 244506-244506.

[40] IUPAC. Compendium of Chemical Terminology, 2nd ed. (the "Gold Book"). Compiled by A. D. McNaught and A. Wilkinson. Blackwell Scientific Publications, Oxford (1997). XML online corrected version: http://goldbook.iupac.org (2006-) created by M. Nic, J. Jirat, B. Kosata; updates compiled by A. Jenkins. ISBN 0-9678550-9-8.

[41] http://lammps.sandia.gov

[42] S. Plimpton, Fast Parallel Algorithms for Short-Range Molecular Dynamics, J Comp Phys, 117, 1-19 (1995).

[43] Manga, Venkateswara Rao, et al. "Molecular dynamics simulations and thermodynamic modeling of $\mathrm{NaCl}-\mathrm{KCl}-\mathrm{ZnCl} 2$ ternary system." Calphad 46 (2014): 176-183.

[44] Freyland, W. Liquid Metals, Molten Salts, and Ionic Liquids: Some Basic Properties.

In Coulombic Fluids ,Springer Berlin Heidelberg. pp. 5-44 (2011)

[45] Morgan, Dane, and Jacob Eapen. Modeling Solute Thermokinetics in LiCI-KCI Molten Salt for Nuclear Waste Separation. No. 10-938. Battelle Energy ALliance LLC, 2013.

[46] Kato T, Inoue T, Iwai T, et al. Separation behaviors of actinides from rare-earths in molten salt electrorefining using saturated liquid cadmium cathode $[\mathrm{J}]$. Journal of Nuclear materials, 2006, 357(1): 105-114.

[47]A. Jain*, S.P. Ong*, G. Hautier, W. Chen, W.D. Richards, S. Dacek, S. Cholia, D. Gunter, D. Skinner, G. Ceder, K.A. Persson (*=equal contributions) The Materials Project: A materials genome approach to accelerating materials innovation APL Materials, 2013, 1(1), 011002.

[48] Watanabe M, Reinhardt W P. Direct dynamical calculation of entropy and free energy by adiabatic switching[J]. Physical review letters, 1990, 65(26): 3301.

[49] Castrillejo Y, Bermejo M R, Barrado E, et al. Solubilization of rare earth oxides in the eutectic $\mathrm{LiCl}-\mathrm{KCl}$ mixture at $450 \mathrm{C}$ and in the equimolar $\mathrm{CaCl}_{2}-\mathrm{NaCl}$ melt at $550 \mathrm{C}[\mathrm{J}]$. Journal of Electroanalytical Chemistry, 2003, 545: 141-157.

[50] Fusselman S P, Roy J J, Grimmett D L, et al. Thermodynamic properties for rare earths and americium in pyropartitioning process solvents[J]. Journal of the Electrochemical Society, 1999, 146(7): 2573-2580.

[51] Castrillejo Y, Hernández P, Rodriguez J A, et al. Electrochemistry of scandium in the eutectic LiCl-KCl[J]. Electrochimica Acta, 2012, 71: 166-172.

[52] Pankratz L B. Thermodynamic properties of halides[M]. United States Department of the Interior, Bureau of Mines, 1984.

[53] Bermejo M R, Gómez J, Martínez A M, et al. Electrochemistry of terbium in the eutectic LiCl-KCl[J]. Electrochimica Acta, 2008, 53(16): 5106-5112.

[54] E. E. Shpil'rain, V. I. Shkermontov, S. N. Skovorod'ko, and A. G. Mozgovoi, "Activity of the components of binary alloys of alkali metals: Na-K system", High temperature, 40(1), 33 (2002).

[55] Shpil'rain E E, Shkermontov V I, Skovorod'ko S N, et al. Activity of the components of binary alloys of alkali metals: $\mathrm{Na}-\mathrm{K}$ system[J]. High temperature, 2002, 40(1): 33-43. 
[56] H. Miyashiro, in: Proc. Information Exchange Meeting on Actinide and Fission Product Separation and Transmutation, OECD Nuclear Energy Agency, Mito City, Japan, November 6-8, 1990.

[57] Konings R J M, Malmbeck R, Serp J. Evaluation of thermochemical and electrochemical data for the pyrochemical partitioning process[J]. Journal of Nuclear Science and Technology, 2002, 39(sup3): 906-909.

[58] Sridharan K, Martin S, Mohammadian M, et al. Thermal properties of LiCl-KCl molten salt for nuclear waste separation[J]. Transactions of the American Nuclear Society, 2012, 106: 12401241.

[59] Lantelme F, Berghoute Y. Electrochemical Studies of $\mathrm{LaCl}_{3}$ and $\mathrm{GdCl}_{3}$ Dissolved in Fused LiCl-KCl[J]. Journal of the Electrochemical Society, 1999, 146(11): 4137-4144.

[60] Fabian C P, Luca V, Chamelot P, et al. Experimental and simulation study of the electrode reaction mechanism of $\mathrm{La} 3+$ in $\mathrm{LiCl}-\mathrm{KCl}$ eutectic molten salt[J]. Journal of The Electrochemical Society, 2012, 159(4): F63-F67.

[61] Fusselman S P, Roy J J, Grimmett D L, et al. Thermodynamic properties for rare earths and americium in pyropartitioning process solvents[J]. Journal of the Electrochemical Society, 1999, 146(7): 2573-2580.

[62] Castrillejo Y, Bermejo M R, Martínez A M, et al. Electrochemical behavior of lanthanum and yttrium ions in two molten chlorides with different oxoacidic properties: The eutectic $\mathrm{LiCl}$ $\mathrm{KCl}$ and the equimolar mixture $\mathrm{CaCl}_{2}-\mathrm{NaCl}[\mathrm{J}]$. Journal of Mining and Metallurgy, Section B: Metallurgy, 2003, 39(1-2): 109-135.

[63] Matsumiya M, Matsumoto S. Electrochemical studies on lanthanum ions in molten LiClKCl-eutectic mixture[J]. Zeitschrift für Naturforschung A, 2004, 59(10): 711-714.

[64] Iizuka M. Studies on electrorefining and electroreduction processes for nuclear fuels in molten chloride systems[J]. 2010.

[65] Saboungi, MarieLouise, and Milton Blander. "Conformal ionic solution theory for additive ternary molten-ionic systems." The Journal of Chemical Physics63.1 (1975): 212-220. [66] A Statistical Mechanical Theory for Activity Coefficients of a Dilute Solute in a Binary Solvent 